\title{
The Impact of Terrorist Attacks in G7 Countries on International Stock Markets and the Role of Investor Sentiment*
}

\author{
Panayiotis Papakyriakou $^{\mathrm{a}}$ \\ University of Southampton
}

Athanasios Sakkas ${ }^{b}$

University of Southampton

Zenon Taoushianis $^{c}$

University of Cyprus

January 2019

\footnotetext{
* We thank the University of Southampton for a research grant. We also thank Dimitris Petmezas, Nihat Aktas, Antonios Kalyvas, Abhishek Ganguly, several anonymous referees and participants at the Paris Financial Management Conference of 2018 for useful feedback and comments. Remaining errors are our own.

${ }^{a}$ Contact address: Department of Banking and Finance, Southampton Business School, University of Southampton, Southampton SO17 1BJ, UK. Email: p.papakyriakou@soton.ac.uk

${ }^{\mathrm{b}}$ Contact address: Department of Banking and Finance, Southampton Business School, University of Southampton, Southampton SO17 1BJ, UK. Email: a.sakkas@ soton.ac.uk

${ }^{\mathrm{c}}$ Contact address: Department of Accounting and Finance, School of Economics and Management, University of Cyprus, P.O. Box 20537, CY 1678 Nicosia, Cyprus. taoushianis.zenon@ucy.ac.cy
} 


\title{
The Impact of Terrorist Attacks in G7 Countries on International Stock Markets and the Role of Investor Sentiment
}

\begin{abstract}
We consider terrorism acts in G7 countries over the period 1998 - 2017 and examine their impact on a sample of stock market indices from 66 countries. Using an event-study methodology we find that stock markets decline significantly on the event day and on the following trading day. We further consider the investor sentiment following the attacks, based on the content of country-level news stories and social media sources, and find that indices in countries associated with higher declines in the post-event sentiment, exhibit significantly higher economic losses. Our data and results are robust to several settings; these include using samples of events from different studies, excluding the 9/11 terrorist attack from the sample of events, excluding stock market indices of G7 countries from the sample of equity data and utilizing more sophisticated event-study methodologies.
\end{abstract}

JEL classification: G12, G14, G15

Keywords: terrorism, stock markets, investor sentiment, surprise 


\section{Introduction}

Terrorism incidents are unexpected events that cause fear, shock and bad mood among investors. Such feelings can initiate a panic-selling response and may result in sharp stock market declines (Burch et al., 2016). Since stock prices incorporate investors' expectations, but may also react to sudden unanticipated shocks, the question of whether terrorism incidents affect stock prices and, if so, to what extent, has attracted increasing interest among scholars. While the negative effect of terrorism incidents on stock markets around the world has been widely reported (Chen and Siems, 2004; Eldor and Melnick, 2004; Karolyi and Martell, 2006; Arin et al., 2008; Brounen and Derwall, 2010; Chesney et al., 2011), there is considerably less knowledge on the relation between changes in investor sentiment following terrorism incidents and stock market returns.

In this paper, we undertake a comprehensive analysis of the impact of terrorist attacks on international stock markets, while accounting for changes in the country-level investor sentiment in the days following the attacks. To this end, we consider a contemporary sample of major terrorism events in G7 countries over the period 1998-2017 and examine their impact on an international sample of stock market indices from 66 countries. We employ an event-study methodology and find that, following the attacks, stock markets sustain significant economic losses on the event day and on the trading day following the attacks, but continue to decline, albeit at a slower rate, until trading day 10 post-event.

The main contribution of our study is the consideration of the per-country change in investor sentiment in the aftermath of terrorist attacks. Specifically, we contend that the extent of stock markets' reaction would depend on how investors value terrorism-related information or, 
equivalently, how investor sentiment changes after the attacks. ${ }^{1}$ Indeed, the voluminous and widespread dissemination of information following major terrorist attacks creates a channel that transmits negative feelings and drives the mood and emotions through continuous exposure of disturbing images, videos and exaggerated descriptions (see, for instance, Slone [2000] and Chermak and Gruenewald [2007]). In certain cases, particularly when dealing with disasters such as terrorism events, the way information is communicated is more likely to provoke fear than to inform the public (Anzur, 2000). Slone (2000), in particular, finds a significant increase in the anxiety level of people who have been exposed to actions of terrorism in Israel. Schlenger et al. (2002) find that the 9/11 terrorist attacks, were associated with increased post-traumatic stress disorder. Based on the findings of these studies, one can argue that stock markets in countries with negative change in the post-event sentiment realise larger economic losses. Failure to consider post-event changes in the country-level sentiment may result in an underestimation of the effect on the stock markets of countries with bad investor mood and, respectively, an overestimation of the effect in countries where the sentiment is not affected.

To this end, we employ a unique dataset that gauges the country-level investor sentiment based on news sources. Using our sentiment dataset, we develop a "Surprise" measure to account for the changes in the sentiment following the terrorist attacks. Consistent with our expectations, we find that stock markets in countries with higher declines in the post-event investor sentiment (i.e. countries experiencing a Negative Surprise) sustain significantly larger economic losses relative to the remaining countries. Further, based on graphic representation of our results, we find that

\footnotetext{
1 This argument is supported by studies finding that sentiment and generally mood are associated with investment behavior and stock returns (Saunders, 1993; Hirshleifer and Shumway, 2003; Brown and Cliff, 2005; Schmeling, 2009; Frijns et al., 2017).
} 
stock markets of countries with Positive (non-Negative) Surprise return to the pre-attack levels in a shorter period of time relative to the stock markets of negatively surprised countries which do not seem to recover, even 40 trading days after the attacks.

Our paper updates and extends the existing literature about the effects of terrorism in the following ways. First, it considers a contemporary sample of major terrorism events and examines their impact on a comprehensive sample of stock market indices from 66 countries, which helps us determine the degree of contagion around the globe. In contrast, prior studies have primarily focused on analyzing the contagion effects that single events, like 9/11, have generated on other countries (Carter and Simkins, 2004; Chen and Siems, 2004; Nikkinen at al., 2008) or the impact of several events on a few countries (Brounen and Derwall, 2010; Chesney et al., 2011). In a broad sense, our results show that vulnerabilities or shocks which occur in strong economies are propagated to the rest of the world and, in particular, highlight the impact of G7 countries on the global economy. ${ }^{2}$

Second, we exploit unique per-country daily sentiment data, based on the content of news articles and social media stories. Due to the widespread dissemination of terrorism-related information, sentiment data, based on news sources and social media, are a more representative proxy for investor sentiment. Such data provide a unique framework for measuring stock market reaction more accurately by using each country's own sentiment. We believe that the investor sentiment we use is an important component which we suggest future studies should also employ to examine the effect of various shocks in the stock markets or generally in the economy. To the best of our

\footnotetext{
${ }^{2}$ In contrast, the consensus is to examine how shocks only from the US are transmitted to other countries (see, for instance, Samarakoon, [2011], Jones and Olson [2015] and Papakyriakou et al. [2018]).
} 
knowledge, this is the first comprehensive study that investigates the link between investor sentiment following events of terrorism and the reaction of stock markets globally.

The remainder of the paper is organized as follows. In section 2, we review related research and develop the hypotheses, in section 3, we describe the data and in section 4, we detail the methodology. In section 5, we present the results of the main analysis, in section 6 we discuss results from several additional tests. Section 7 concludes the paper.

\section{Related research and hypothesis development}

\subsection{Do terrorist attacks affect global stock market indices?}

In the aftermath of the attacks on September 11, 2001 (9/11), the Dow Jones Index sustained losses that exceeded 7\% upon the reopening of US stock markets six days later (Brounen and Derwall, 2010). The effect of the attack was far more pronounced in the airline industry (Carter and Simkins, 2004; Chesney et al., 2011). Similarly, the MSCI World Index dropped by more than 4.5\% in the first days after the 9/11 event, whereas after the Madrid attacks on 11 March 2004, it dropped by $1.72 \%$ (Drakos, 2010). There is a plethora of evidence suggesting a negative effect in global stock markets following terrorist attacks (see also Nikkinen et al., 2008; Chesney et al., 2011). Furthermore, prior studies find that the markets recover within the first week of the aftermath (Brounen and Derwall, 2010) with others finding that such recovery could take up to a month (Johnston and Nedelescu, 2006). Finally, some studies find that markets do not return to their previously traded levels in the foreseeable horizon (Eldor and Melnick, 2004).

In this paper, we update the existing literature by examining the impact of major terrorist attacks in G7 countries, over the period 1998-2017, on a comprehensive sample of stock market indices from 66 countries. The consideration of terrorist attacks in G7 countries is important in our analysis 
because we expect the shocks that these attacks inflict on the strongest economies of the world to stimulate high uncertainty, lead to questions on global safety, and increase the fear and uncertainty among investors globally. Subsequently, stock markets are expected to decline, thus informing our first hypothesis.

Hypothesis 1: Terrorist attacks in G7 countries will generate strong negative abnormal returns on international stock markets.

2.2. Do countries with negative changes in the investor sentiment after terrorist attacks, experience larger declines in their stock markets?

Catastrophic events generate anxiety among investors which in turn can affect their investment behavior - for example, their risk preferences and, consequently, asset prices. In the aftermath of aviation disasters, Kaplanski and Levy (2010) find a significant negative effect in the US stock markets and suggest that increased anxiety is to blame. There is, however, inconclusive evidence as to whether investors shift towards safer assets, such as US treasury bills or the US dollar. In the case of terrorism incidents though, Wang and Young (2017) find that investors do shift their risky investments towards safer securities, such as government bonds. Furthermore, Nikkinen and Vahamaa (2010) find a negative shift of the probability density functions implied by option prices, which in fact reflect the negative outlook anticipated by market participants, after three major terrorist attacks (9/11, Madrid 2004 attacks and London 2005 attacks). Analyzing closed-end fund discounts, Burch et al. (2003) document that such discounts significantly increased after the 9/11 attacks, concluding that they carry the sentiment of small investors. Using questionnaires to gauge investors' expectations, Glaser and Weber (2005) document that German investors' expectations for future returns after the $9 / 11$ attacks were higher. Because the questionnaire was disseminated 
in the weeks following the $9 / 11$ events, the finding is attributed to the fact that investors expected a mean reversion. Finally, Drakos (2010) shows that the psychosocial impacts caused by the attacks amplify the negative effects of terrorism. ${ }^{3}$

Given that terrorist attacks generate bad mood and increased uncertainty, we seek to examine how changes in the investor sentiment affect international stock markets following acts of terrorism. The rapid and extensive spread of information following terrorist attacks, as well as the tone of the media reporting of the events, has a negative impact on investor mood and sentiment and, by implication, stock prices. Given that the sentiment data we use are based on a large number of news and social media sources, the fact they are available at country-level, and on a daily basis, affords us a unique framework to measure the post-event change in investor sentiment and examine the impact on international stock markets, conditional on the change of each country's own sentiment. The second hypothesis follows.

Hypothesis 2: The negative abnormal returns generated by terrorist attacks in $G 7$ countries will be more pronounced in stock markets of countries with negative change in the investor sentiment in the post-event period.

\section{Data}

In this paper we employ three sources of data: a) terrorist attacks from the Global Terrorism Database, b) local stock market indices from Thomson DataStream, and c) Marketpsych indices, provided by Thomson Reuters.

\footnotetext{
${ }^{3}$ We dedicate a separate section for this finding in Section 6.3.2.
} 


\subsection{Terrorist attacks in major economies}

We collect our sample of terrorist attacks from the Global Terrorism Database (GTD), which maintains a large record of in excess of 180,000 terrorism incidents anywhere in the world, since $1970 .{ }^{4}$ We choose major events in territories controlled by G7 countries over the period 19982017, because such events are likely to cause fear and may affect investors' decisions. Further, terrorist attacks on such strong economies can lead to questions on global safety and increase uncertainty among investors. We filter out duplicate events (for instance 9/11 is reported four times because the terrorist groups hit at four different locations on the same day) and events that are characterized as ambiguous (i.e. cannot be said with certainty they were acts of terrorism). Imposing these filters yields a sample of 28 terrorist attacks in six target countries (all G7 countries, except for Italy) that we present in Table 1.

\section{[INSERT TABLE 1 HERE]}

\subsection{Local stock market indices}

We source equity data from Thomson DataStream. In total, we take 67 equity return indices from the "DS Market" family of indices. ${ }^{5}$ From these, 66 indices are local (country-level) while the last one is the world index. The world index is the market value-weighted average of all the local-level indices. Most "DS Market" indices start on 1 January 1973 with only a few exceptions which become available in later years. However, since our sample of terrorist attacks is confined within the years from 1998 to 2017, we only use equity data from 1997 onwards. ${ }^{6}$ Further, we report all

\footnotetext{
${ }^{4}$ For more details visit, https://www.start.umd.edu/gtd/

5 "DS Market" is used to denote DataStream's proprietary set of equity indices.

${ }^{6}$ That is because, for the event-study methodology, the estimation data need to extend back some time before the date of the first event in the sample.
} 
indices in US dollars to eliminate noise that may come from foreign exchange rates, a common practice in empirical studies of international financial markets (Pukthuanthong and Roll, 2009). Table 2 provides a comprehensive list of the country-level equity indices we employ.

\section{[INSERT TABLE 2 HERE]}

\subsection{Thomson Reuters Marketpsych Indices and surprise}

In our study, we use the Thomson Reuters Marketpsych Indices (TRMI) to account for the country-level investor sentiment. TRMI are available since 1 January 1998 but, depending on the country in question, they may start later. TRMI summarize the content as well as the quantity of economic, political and other country-level news into meaningful daily indices which gauge the overall sentiment and generally other market feelings such as optimism, joy, trust, and fear. These indices are generated by an algorithm developed by Thomson Reuters in collaboration with Marketpsych LLC which identifies news stories from Thomson Reuters News Feed Direct, Factiva News and other third-party news sources, on a real-time basis, and over a 24-hour rolling window. ${ }^{7}$

There are several advantages of using the TRMI. First, the TRMI are available for a large number of countries as opposed to more traditional sentiment measures (Baker and Wurgler, 2006; Yu and Yuan, 2011; Huang et al., 2015), essentially allowing us to measure the post-event change in investor sentiment for all the countries we have equity data for. This is particularly important in the light of countries such as Syria and Afghanistan which are known warzones, or even the case of Mexico where the drug war claims the lives of tens of thousands of people every year. Such countries are less likely to react to terrorism (or similar human-loss related) news to the same

\footnotetext{
${ }^{7}$ Countries without TRMI data are Luxembourg, Slovakia and Slovenia. For further information on the TRMI indices, visit https://www.marketpsych.com
} 
extent as more peaceful territories. We further posit that our sentiment data are more relevant compared to more traditional (event-specific) terrorism intensity measures because they can be used to filter out those countries that are more resilient to terrorism-related news. Second, the TRMI are based on a very large number of news sources, suggesting that the indices are comprehensive, efficient and reliable (Huang et al., 2018). Third, the TRMI are flexible as they are available for different sources of news: traditional news, social media and combined. ${ }^{8}$

Among the TRMI family, we use the overall per-country Sentiment index for inference. The Sentiment is generated by an algorithm that classifies and then ranks news stories on a continuous scale between -1 and +1 (i.e. negative to positive), depending on the tone and the choice of words in the news stories. Using this index, we construct a Surprise measure based on the changes in the sentiment following terrorist attacks. The procedure consists of the following steps. First we estimate the abnormal sentiment by subtracting the average sentiment of trading days -10 to -2 inclusive, from the raw sentiment of days 0 and +1 . Then we add the abnormal sentiments on days 0 and +1 to get the Cumulative Abnormal Sentiment (CAS). Finally, for countries with negative CAS, we assume a Negative Surprise while, for the rest of the countries, we assume a Positive (non-Negative) Surprise.

\section{Methodology}

\subsection{Event-study}

As a first step, we implement a short-horizon event-study analysis, an approach regarded as straightforward and trouble-free (Kothari and Warner, 2007). To ensure the robustness of our results, we adapt the steps in Michaelides et al. (2015) to the standards of our study. We estimate

\footnotetext{
${ }^{8}$ Our results are based on the combined dataset. Results for the other two datasets can be provided upon request.
} 
the Capital Asset Pricing Model (CAPM) using country stock market returns as the dependent variable and the world market returns as the independent variable. We choose the estimation period to cover the interval of $(-100,-11)$ trading days, relative to event day $0 .{ }^{910}$ Specifically, we estimate the following equation.

$$
\begin{aligned}
& \boldsymbol{R}_{i t j}=\boldsymbol{a}_{i j}+\boldsymbol{\beta}_{i j} \boldsymbol{R}_{W t j}+\varepsilon_{i t j} \quad-10 \leq t \leq+10 \\
& j=1,2, \ldots, 28 \text {. }
\end{aligned}
$$

$R_{i t j}$ is the stock market return of country " $i$ ", on day " $t$ ", relative to the event " $j$ ". $R_{W t j}$ is the return of the world index on day " $t$ ", relative to event " $j$ ".

Once estimated, we use the coefficients from Equation (1) to calculate abnormal returns (AR) in the event window $(-10,+10)$. We define abnormal returns $(A R)$ as the difference of actual (raw) and expected returns:

$$
\boldsymbol{A} \boldsymbol{R}_{i t j}=\boldsymbol{R}_{i t j}-\widehat{\boldsymbol{a}}_{\boldsymbol{i j}}-\widehat{\boldsymbol{\beta}}_{\boldsymbol{i j}} \boldsymbol{R}_{\boldsymbol{W} \boldsymbol{j} j} \quad \begin{gathered}
i=1,2, \ldots, 66 \\
-10 \leq t \leq+10 \\
j=1,2, \ldots, 28
\end{gathered}
$$

We obtain the cumulative abnormal return over the interval $\left(\mathrm{t}_{1}, \mathrm{t}_{2}\right)$, as follows.

$$
\begin{array}{cc}
\boldsymbol{C A R}_{\boldsymbol{i} \boldsymbol{j}}\left[\boldsymbol{t}_{1}, \boldsymbol{t}_{2}\right]=\boldsymbol{A} \boldsymbol{R}_{\boldsymbol{i}, \boldsymbol{t} \mathbf{1}, \boldsymbol{j}}+\cdots+\boldsymbol{A} \boldsymbol{R}_{\boldsymbol{i}, \boldsymbol{t} 2, \boldsymbol{j}} & i=1,2, \ldots, 66 \\
j=1,2, \ldots, 28 \\
-10 \leq t_{1} \leq t_{2} \leq+10
\end{array}
$$

Then we estimate the equally weighted average (across all event-country observations) cumulative abnormal return $(A C A R)$ over the same interval, as follows.

$$
\boldsymbol{A C A R}\left[\boldsymbol{t}_{1}, \boldsymbol{t}_{2}\right]=\frac{\mathbf{1}}{\boldsymbol{n} * \boldsymbol{m}} \sum_{i=1}^{n} \sum_{j=1}^{\boldsymbol{m}} \boldsymbol{C A R}_{\boldsymbol{i j}}\left(\boldsymbol{t}_{1}, \boldsymbol{t}_{2}\right) \quad \begin{gathered}
-10 \leq t_{1} \leq t_{2} \leq+10 \\
n=66, m=28
\end{gathered}
$$

\footnotetext{
${ }^{9}$ We follow Brounen and Derwall (2010) in choosing the estimation and event windows.

${ }^{10}$ Event day 0 is the actual date of the terrorism incident, if a working day, or the first working day following the actual day of the incident, if not a working day.
} 
The next step involves the standardization of abnormal returns in the event window to account for event-induced variance. This method, first proposed by Boehmer et al. (1991), takes AR in the event window (Equation (2)) and divides them by the time series standard deviation of the residuals (abnormal returns) from the estimation period $(-100,-11)$. The steps we follow to estimate the standardized abnormal returns (SAR hereafter) are described in Equations (5)-(7).

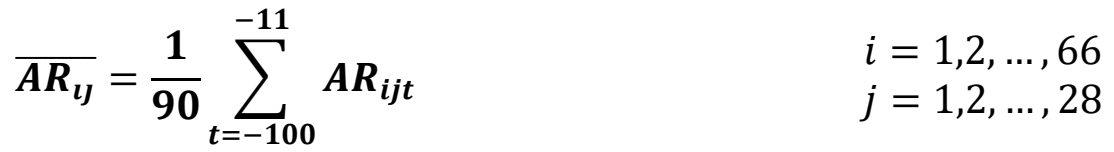

$$
\begin{aligned}
& \overline{\boldsymbol{s}_{\imath \boldsymbol{j}}}=\sqrt{\frac{\mathbf{1}}{\mathbf{8 9}} \sum_{\boldsymbol{t}=-100}^{-11}\left(\boldsymbol{A R} \boldsymbol{R}_{i j t}-\overline{\boldsymbol{A R}}\right)^{2}} \quad \begin{array}{l}
i=1,2, \ldots, 66 \\
j=1,2, \ldots, 28
\end{array}
\end{aligned}
$$

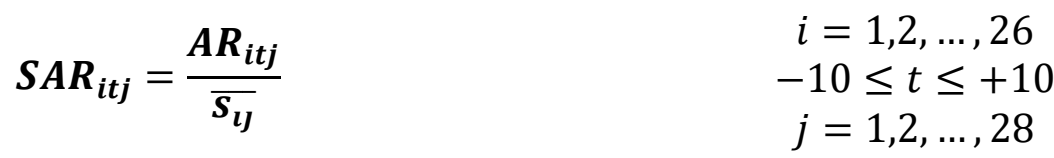

Finally, the test statistic of Boehmer et al. (1991) is given by Equation (8).

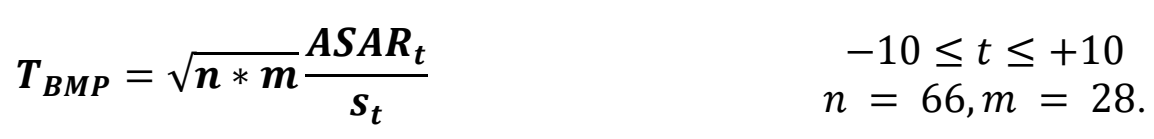

The formula used to estimate Average Standardized Abnormal Returns (ASAR), the numerator of $\mathrm{T}_{\mathrm{BMP}}$, is provided below.

$$
\boldsymbol{A S A R}=\frac{1}{\boldsymbol{n} * \boldsymbol{m}} \sum_{i=1}^{n} \sum_{j=1}^{\boldsymbol{m}} \boldsymbol{S A R _ { i t j }} \quad \begin{gathered}
-10 \leq t \leq+10 \\
n=66, m=28
\end{gathered}
$$

The denominator of $\mathrm{T}_{\mathrm{BMP}}$ is estimated as follows.

$$
\boldsymbol{s}_{\boldsymbol{t}}=\sqrt{\frac{1}{\boldsymbol{n} * \boldsymbol{m}} \sum_{i=1}^{n} \sum_{j=1}^{m}\left(\boldsymbol{S A R} \boldsymbol{R}_{i t j}-\boldsymbol{A S A R}\right)^{2}} \quad \begin{gathered}
-10 \leq t \leq+10 \\
=66, m=28
\end{gathered}
$$


Finally, we estimate the test-statistic of Kolari and Pynnonen (2010), which is an extension of the Boehmer et al. (1991) test statistic. ${ }^{11}$ The difference is that the KP statistic also takes into consideration the average sample cross-correlation of the estimation period of residuals $(\bar{r})$. KP shows that, if the $\bar{r}$ is not accounted for, then the resulting test-statistic would tend to over-reject the null hypothesis of zero abnormal returns. The KP test-statistic is estimated in Equation (11).

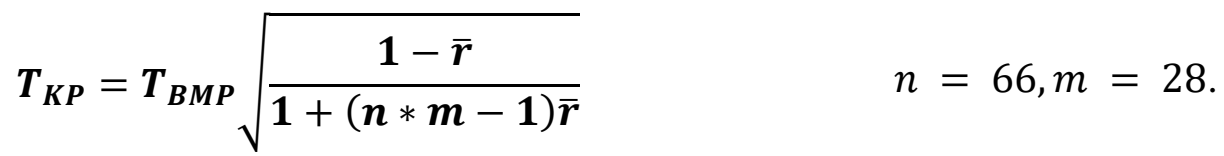

It is useful to note that we estimate test-statistics (Equations (8) and (11)) assuming that abnormal returns (Equation (2)) are independent and identically distributed random variables following the Gaussian distribution with mean zero and variance $\sigma^{2}$. As such, the test statistics are assumed to asymptotically approach the standard Gaussian distribution, provided that the number of eventcountry observations on day $\mathrm{t}$ (relative to the event) is sufficiently large. ${ }^{12}$

\subsection{Regression analysis}

For the regression analysis, we develop a multivariate OLS regression model, given in Equation (12), to identify whether the investor sentiment, upon which our measure of Surprise is based, is related with stock market returns.

$$
A R_{i t j}=\beta_{0}+\beta_{1} * A S_{i t j}+\beta_{2} * \operatorname{Vol}_{i t j}+\beta_{3} * L i q_{i t j}+\eta_{i}+\lambda_{j}+\varepsilon \quad \begin{array}{r}
i=1,2, \ldots, 66 \\
j=1,2, \ldots, 28 \\
0 \leq t \leq+10
\end{array}
$$

\footnotetext{
${ }^{11}$ In the tables of results we only report the test statistics of Kolari and Pynnonen (2010). The test statistics of Boehmer et al. (1991) are not tabulated but can be provided upon request.

${ }^{12}$ Note that while for Equations (8) and (11) the number of event-country observations is assumed to be 1848 (i.e. 28 events x 66 stock market indices) the actual number is smaller (i.e. equal to 1799) due to the fact that, for some of the earlier events, some countries do not have equity data. This difference is acknowledged and accounted for in the calculations which generate the results.
} 
The Abnormal Return (AR) is the dependent variable, defined in Equation (2). The subscript " $i$ " enumerates the countries (stock markets) in the sample of equity data while subscript " $j$ " enumerates the terrorist attacks. In this instance, we consider the response of stock markets following the attacks only; hence, " $t$ " ranges from 0 to 10 . The element " $\beta_{0}$ " represents the intercept while the element " $\beta_{1}$ " is the coefficient of the Abnormal Sentiment (AS), the main explanatory variable. The Abnormal Sentiment (AS) on trading day " $t$ " is estimated by subtracting from the raw sentiment of that day, the average raw sentiment of trading days -10 to -2 inclusive. Further, the component " $\beta_{2}$ " is the coefficient of the forecasted, via a GARCH $(1,1)$ process, daily volatility $(\mathrm{Vol})$ of stock market returns whereas " $\beta_{3}$ " is the coefficient of a stock market liquidity (Liq) proxy, estimated as the ratio of daily turnover by value over total market value. It should be noted that Equation (12) is estimated in a stepwise fashion. For the first estimation only the main explanatory variable (AS) is included, while progressively more variables are added (Vol and Liq) in the second and third estimations, respectively. We address omitted variable bias concerns by employing indicator variables at the country and event levels (parameters " $\eta_{i}$ " and " $\lambda_{j}$ ", respectively). The parameter $\varepsilon$ represents the error terms, assumed to be heteroskedastic (WhiteHuber standard errors are used to control for that).

\section{Main analysis}

In this section we discuss the results of our main analysis, generated by applying the event-study methodology (Section 4.1) to our data. In summary, we consider several windows of cumulative abnormal stock market returns timed before, after and around our sample of terrorist attacks. 


\subsection{Graphical representation of findings}

Before discussing the results generated by our event-study analysis, it is useful perhaps to first construct a graphical representation of how stock markets react to terrorism. Figure 1 contains plots for a) the full sample of observations (overall case), b) the subsample of markets with Negative Surprise, and c) the subsample of markets with Positive Surprise in the time window [$10,+10]$, around the event. ${ }^{13}$

\section{[INSERT FIGURE 1 HERE]}

The graph of the overall case shows that stock market indices experience a sharp decline following terrorism acts, with most of the losses materializing on event day and the next trading day. After that, stock markets stabilize, but continue following a (more gradual) downward route until trading day +10 . The sample of indices with Negative Surprise exhibit more interesting results, as these markets react more strongly, compared to the overall case. Finally, the sample of indices with Positive Surprise also decline but the response is seemingly milder relative to the Overall and Negative Surprise cases.

\subsection{Event-study: Overall case}

For the event-study results in the overall case, we consider the response of the 66 international stock market indices (in Table 2) to 28 terrorist attacks (in Table 1) and present results in Table 3. Several time windows of Average Cumulative Abnormal Returns (ACAR) are statistically and economically significant. These are the $[0,+1],[0,+2],[0,+3],[0,+5],[0,+10],[+1,+2],[+1,+3]$,

\footnotetext{
${ }^{13}$ It should be noted that while all the 28 terrorist attacks in our sample are used to generate results, not all countries have Sentiment data, needed for the Surprise cases. Hence the number of event-country observations for the overall case is slightly higher compared to the two Surprise case (refer to Tables 1 and 2 for further details).
} 
$[+1,+5]$ and $[+1,+10]$, with cumulative abnormal returns estimated at $-0.414 \%,-0.442 \%$, $0.491 \%,-0.536 \%,-0.538 \%,-0.254 \%,-0.304 \%,-0.348 \%$ and $-0.35 \%$, respectively. The results suggest that, on average, the response of international stock markets to terrorism acts in G7 countries is immediate but also short-lived as none of the windows starting on trading day +2 or later is significant. In total, the results support our first hypothesis; that after terrorist attacks in G7 countries, international stock market indices experience sharp declines. Note that in the period that precedes the event, all time windows are statistically insignificant, suggesting that the change documented post-event is terrorism-related.

\subsection{Event-study: Investor sentiment}

Table 3 (middle column) presents ACAR for the case of stock markets in countries with a Negative Surprise post-event. The time windows $[0,+1],[0,+2],[0,+3],[0,+5],[0,+10],[+1,+2]$, $[+1,+3],[+1,+5]$ and $[+1,+10]$ exhibit significant and negative stock market reaction, with ACAR estimated at $-0.508 \%,-0.553 \%,-0.613 \%,-0.592 \%,-0.642 \%,-0.287 \%,-0.347 \%,-0.326 \%$ and $0.376 \%$, respectively. Besides significant, the losses are also persistent as they continue to accumulate without signs of reversal for at least 10 trading days post-event. However, after relative day +1 , the decline is less pronounced and bears little economic and statistical significance, indicating that markets stabilize shortly after the occurrence of terrorism, even in cases of Negative Surprise. Overall, the results are consistent with the second hypothesis; that is, markets with negative change in the investor sentiment following terrorist attacks in G7 countries are associated with significantly stronger economic losses. Finally, in the 10-day window that precedes the event, we do not document statistically significant ACAR in any of the cases we examine, indicating that our methodology is robust and that our measure for Surprise efficiently captures (and isolates) the negative effect of terrorism on stock market returns. 


\section{[INSERT TABLE 3 HERE]}

\section{Additional analysis}

In order to test the accuracy of our main analysis results we run several additional tests which we classify in four categories. In the first category of tests, we assess the quality of our sample of terrorism events. In the second category, we test the robustness of our Surprise measure, and in the third category we compare the results of our baseline event-study methodology with several alternatives developed in past literature. Finally, this paper benefits from regression analysis, as a means of supporting the assumption that investor sentiment and stock market returns are related.

\subsection{Testing the sample of events}

\subsubsection{Removing equity data from $G 7$ countries}

Because we consider terrorist attacks in G7 countries, one could argue that the results are driven by the response of stock markets in G7 countries, as these countries were the targets. To address these concerns, we exclude the stock indices from the seven G7 countries from the sample of equity data and repeat the analysis. Our results suggest that the response in non-G7 countries (Table 4, Overall ex G7) is slightly stronger than the Overall case (Table 4, Overall). This finding is very interesting and supports the argument that terrorist attacks have a strong contagion effect on non-target countries.

\subsubsection{Removing the $9 / 11$ terrorist attack}

In order to address concerns that the major terrorism event of September 11, 2001 in the United States may be driving the results, we remove it from the sample of events and repeat the analysis, reporting results in Table 4 (Overall ex 9/11). The results, albeit slightly less significant, remain 
in the same direction, retaining their economic and (in most cases) statistical significance. In total, our results are robust to removing the 9/11 terrorism event from the initial sample of events.

[INSERT TABLE 4 HERE]

\subsubsection{Filtering out proximal events}

Prior literature on event-studies has devised ways of correctly measuring the effect from events occurring close to one another timewise. For instance, Michaelides et al. $(2015,2018)$, who explore the effect of sovereign rating downgrades on stock and foreign exchange markets, filter out those events that supersede other (same type of) events for a period of 21 trading days (one calendar month). In this manner the authors isolate the pure effect of events because, as they argue, followup events are not as impactful as the ones preceding them. We adapt this procedure and filter out of our sample of terrorist attacks those attacks that follow other attacks within 4.5 calendar months' time (roughly, our event-study's estimation period). Following this filtering, our initial sample of 28 events is reduced to $11 .{ }^{14}$ Notice that we also remove the $9 / 11$ terrorist attack because of its large scale. ${ }^{15}$ The results follow below.

\section{[INSERT TABLE 5 HERE]}

The results in Table 5 are stronger in economic significance terms than those in Table 3 (i.e. the ACAR are more negative). We postulate that there are at least two reasons for this. First, considering events that occur shortly after other events can potentially decrease the significance of the results in the post-event window. That is because some event-study methodologies (ours

\footnotetext{
${ }^{14}$ The remaining events are numbers $1,2,5,6,7,9,10,12,14,15$ and 22 in Table 1.

${ }^{15}$ Since the remaining sample of events is relatively small, including the very influential $9 / 11$ attack would hugely increase the significance of our results. Hence, we remove it to avoid this situation.
} 
included) base the test statistics on the standard deviation of the residuals in the estimation period. When other events occur in the estimation period, the volatility in stock returns can increase, subsequently reducing the value (and the significance) of the reported t-stats. Second, the sample that we use to generate results in this section excludes the most recent events which, we argue, carry little economic significance relative to older events. This is because terrorist attacks have become far more frequent and violent in recent times and, due to this increased intensity, investors have become more resilient to this kind of news and do not react as strongly as before. This view is also in line with findings in prior literature (see, for example, the discussion in Markoulis and Katsikidis [2018]).

\subsubsection{Samples of events from other studies}

As an additional test, we adopt two alternative samples from two different studies on terrorism (Brounen and Derwall, 2010; Chesney et al., 2011), and repeat the event-study analysis for each of the two samples separately.

The sample from Brounen and Derwall (2010) consists of 31 terrorist attacks over the period 1991-2005 which directly relate to, but have not necessarily happened in, countries with major economies. Applying our baseline event-study methodology to the sample of Brounen and Derwall generates results that are similar to or stronger than ours, demonstrating high statistical and economic significance. The results from Brounen and Derwall's (2010) sample are provided in Table 6 (equivalent to Table 3).

\section{[INSERT TABLE 6 HERE]}

The sample from Chesney et al. (2011) consists of 77 terrorist attacks between 1994 and 2005, in both developed and developing countries. Applying our baseline event-study methodology to 
Chesney et al.'s (2011) sample yields results similar to our own, although, under certain circumstances, the former are slightly less significant. Chesney et al.'s (2011) results are provided in Table 7 (equivalent to Table 3). ${ }^{16}$

\section{[INSERT TABLE 7 HERE]}

Finally, we argue that since the two alternative samples of events we choose to test generate similar results to ours, then our sample of terrorism events is comprehensive, well-selected, and robust.

\subsection{Testing the event-study methodology}

\subsubsection{Considering additional global factors}

As an additional test to our event study methodology, we use the global version of Carhart's (1997) four-factor model to estimate expected returns (rather than using the conventional CAPM), keeping everything else unchanged. The results are reported in Table 8 and are similar to those in Table 3, albeit slightly less significant. Overall our main results are robust to this test.

\section{[INSERT TABLE 8 HERE]}

\subsubsection{Accounting for Beta instability}

Our estimates of CAPM-betas could be subject to variation over time, thus adding uncertainty to our results. To address this concern, we re-run our event study by setting the coefficient for the market risk factor equal to unity and report the results in Table 9. The results are amplified so they

\footnotetext{
${ }^{16}$ It should be noted that, in Table 7, there are three cases of time windows (prior the event) in which the corresponding ACAR appears to be statistically significant. We attribute the significance to a type I error.
} 
become economically more significant but, qualitatively, the inference is unchanged. Overall, our main results remain robust in this test.

\section{[INSERT TABLE 9 HERE]}

\subsubsection{Switching regimes}

In this part, we discuss an extension of the "first mover" filtering in Michaelides et al. (2015, 2018), also discussed in Section 6.1.3, which is a method of removing disturbances of the same type of event from the estimation window of an event-study. The counter-argument here is that while the "first mover" may work well for events of the same type, it does not necessarily hold true for all types of events. In other words, there may be other "irrelevant" events in the estimation window which can potentially generate shocks, increasing the standard deviation of the residuals. To address this concern we consider a two-state market model that accounts for high and low volatility regimes, during the estimation period, similar to Aktas et al. (2007). ${ }^{17}$ The test-statistic in Aktas et al. (2007) is the same as the test-statistic of Boehmer et al. (1991), also given in Equation (8), with the only difference being that the standard errors are estimated from the standard deviation of the low variance regime. Other differences include the extended estimation window $(-250,-25)$, to match the one in Aktas et al. (2007), and also the added flexibility of changing estimated regression coefficients between the two regimes. ${ }^{18}$ Results are reported in Table 10.

\section{[INSERT TABLE 10 HERE]}

\footnotetext{
${ }^{17} \mathrm{We}$ are thankful to an anonymous referee for making this recommendation.

${ }^{18} \mathrm{We}$ are indebted to Nihat Aktas for giving us detailed guidance for implementing the methodology in his paper.
} 
Compared to Table 3, the results generated by this methodology are similar. There are some differences, with the most notable one being the smaller gap between the ACAR of the Negative and Positive Surprise cases. Even then, the Negative Surprise case maintains a small edge in the first days following the events. In all, the results from applying Aktas et al. (2007) methodology to our data support both our hypotheses.

\subsubsection{Placebo test (random date events)}

In order to further test the robustness of our methodology, we perform a placebo test, where we pick 28 random dates over the period 1998-2017 (to match the size and time span of our own sample of events) and generate the equivalent of Table 3 (overall case only). The test generates ACAR that are indistinguishable from zero, a) suggesting the correct implementation of our eventstudy methodology, and b) that the adverse reaction of international stock markets in the postevent period is a true effect of terrorism acts and is not generated by other unrelated incidents or news. ${ }^{19}$

\subsection{Testing the Surprise measure}

\subsubsection{An alternative measure for Surprise}

In this section, we test the robustness of our Surprise measure (introduced in Section 3.3) by constructing an alternative measure that we base on the post-event Cumulative Difference in Sentiment (CDS). For the calculation procedure, first we estimate the difference in sentiments (DS) on days 0 and +1 , defined as $D S_{t}=$ Sentiment $_{t}-$ Sentiment $_{t-1}$. Then, we sum the DS of days 0 and +1 to get the CDS. If the CDS of a country is negative, we assume a Negative Surprise. Alternatively, if CDS is non-negative, we assume a Positive (non-Negative) Surprise. Table 11

\footnotetext{
${ }^{19}$ Results from the placebo test remain untabulated but can be provided by the authors upon request.
} 
contains the results, when repeating the event-study analysis using the alternative measure for Surprise. Because the results are qualitatively identical to those of Table 3, we contend that our main measure for Surprise is robust to this test.

\section{[INSERT TABLE 11 HERE]}

\subsubsection{Accounting for human loss}

One can argue that our sentiment measures are reflective of the severity of the terrorist attacks (i.e. the number of fatalities could be responsible for sentiment changes). With respect to that, prior literature (Eldor and Melnick, 2004; Eldor et al., 2012) finds that the effect of terrorist attacks on stock market returns increases as the number of casualties and fatalities increases. Furthermore, Drakos (2010) explores the association of terrorist attacks with stock market returns, based on the psychosocial impact that the attacks cause. The author reports that the Global Terrorism Database, which we also use, ranks terrorist attacks based on their level of psychosocial impact as major, moderate, minor and null. Upon closer inspection of the database's website, we find this information is no longer available. However, one possibility is that the database based the psychosocial filter on the loss-of-human-life numbers.

To control for the aforementioned issue, we regress our measure of Cumulative Abnormal Sentiment (discussed in Section 3.3) on the natural logarithm of fatalities, also accounting for country and event heterogeneity. Next, we calculate the residual of Cumulative Abnormal Sentiment (CAS) by subtracting the fitted (estimated) CAS from the actual one. Finally, we estimate Surprise (discussed in Section 3.3) using the residual CAS, instead of the actual CAS, and report results in Table 9. Overall the results in Table 9 are comparable to those of Table 3 , 
although the differences between the negative and positive cases are less pronounced. Still, these results suggest that our measure of Surprise is robust to the element of human loss.

\section{[INSERT TABLE 12 HERE]}

\subsection{OLS regression}

The regression analysis is performed as a means of showing that investor sentiment can indeed affect stock market returns in the aftermath of terrorist attacks, even when controlling for event and country specific time-invariant factors as well as stock market daily volatility and liquidity. In particular, we measure the explanatory power of the Abnormal Sentiment (AS) on the Abnormal Return (AR) by estimating Equation (12) using the pooled sample of event-country observations, reporting results in Table $13 .^{20}$

\section{[INSERT TABLE 13 HERE]}

The results in Table 13 suggest that the AS is positively related to the AR, meaning that positive (negative) changes in the Sentiment post-event are associated with more positive (negative) stock market reactions. These results strengthen our event-study findings because they support our argument that, following terrorist attacks, the effect of the sentiment on stock market performance is significant.

\footnotetext{
${ }^{20}$ Table 13 reports two results from two regression estimations. The second result is derived from regressing the Difference in Sentiments (DS), upon which our supplementary measure of Surprise is based, on the Abnormal Return. More discussion on DS is available in Section 6.3.1.
} 


\section{Conclusions}

This study considers a contemporary sample of 28 major terrorist attacks in G7 countries and examines their impact on an international sample of stock market indices from 66 countries.

We employ an event-study methodology and find that, following the terrorist attacks, stock markets sustain significant economic losses with the effect being more pronounced on the event day and the next trading day. After this time period, markets continue to decline more gradually and without showing signs of reversal for up to 10 trading days (two calendar weeks) in the aftermath of the events. We further classify countries by Surprise, proxied by the content of country-level news stories and social media sources, and find that the stock markets of countries with Negative Surprise post-event sustain considerably steeper declines, compared to the overall case. Our event-study results are robust to several settings; these include using samples of events from different studies, excluding the 9/11 terrorist attack from the sample of events, excluding stock market indices of G7 countries from the sample of equity data, and employing more sophisticated event-study methodologies.

This study also benefits from regression analysis. After controlling for time-invariant event and country-specific factors, we demonstrate strong evidence of a positive association between the investor sentiment and the reaction documented in stock markets. This result is in-line with our event-study results, supporting the argument that negatively surprised countries exhibit considerably larger economic losses following terrorist attacks.

Our study has implications for both governments and investors alike, for which we recommend the following remedial actions. First, we propose that countries more vulnerable to terrorist attacks enforce stricter security measures as a means for prevention of both human and economic losses that follow acts of terrorism. Second, to the extent that it is possible, taking measures to reduce 
terrorism incidents would not only have beneficial societal effects but also positive spillovers regarding economic outcomes as, in our case, on stock market performance. Third, we propose that all countries impose measures to regulate the intensity by which terrorism event news (or any other types of negative events news) is reported in the media. Since negative news induces strong adverse effects on stock markets, this measure can help reduce the magnitude of economic losses following acts of terrorism (or other types of disastrous event). From an investor's point of view, it would be wiser to reduce their exposure to countries with negative sentiment. However, conversely, it may also be possible to develop trading strategies to generate profits, following large-scale terrorist attacks in G7 economies. Since the TRMI indices (upon which our measure for Surprise is based) are available on a real-time basis, and over a 24-hour rolling window, our findings can have real-life implications and prove to be beneficial to a wide spectrum of investors. However, because such an expansion also needs to take into consideration several other parameters that may corrode the gains such strategies can generate, for instance transaction costs and foreign exchange rates, we leave this question open for future discourse.

Future work may consider the period following terrorist attacks over an extended horizon and explore the longer-term effects on stock market indices. Some preliminary evidence, illustrated in Figure 2, suggests that the overall decline of stock markets ceases at (about) trading day 10 postevent, stock markets then enter reversal, and all losses are being recovered by (about) trading day 40. It is also interesting to note that in the case of Negative Surprise the losses seemingly persist until trading day 40 post-event without signs of reversal, which calls for more responsive and drastic intervention from the authorities to stabilize financial markets in the countries that respond in this manner. However, because there are also several other factors that need to be taken into consideration in the long run, such as the exponential increase in the volatility of cumulative stock 
market returns, which may render these visual differences insignificant, in order to yield robust inference, we leave this question open for future investigation.

\section{References}

Aktas, N., de Bodt, E., \& Cousin, J. G. (2007). Event studies with a contaminated estimation period. Journal of Corporate Finance, 13(1), 129-145.

Anzur, T. (2000). How to Talk To the Media: Televised Coverage of Public Health Issues in a Disaster. Prehospital and Disaster Medicine, 15(4), 70-72.

Arin, K. P., Ciferri, D., \& Spagnolo, N. (2008). The price of terror: The effects of terrorism on stock market returns and volatility. Economics Letters, 101(3), 164-167.

Baker, M., \& Wurgler, J. (2006). Investor Sentiment and the Cross-Section of Stock Returns. Journal of Finance, 61(4), 1645-1680.

Boehmer, E., Masumeci, J., \& Poulsen, A. B. (1991). Event-study methodology under conditions of event-induced variance. Journal of Financial Economics, 30(2), 253-272.

Brounen, D., \& Derwall, J. (2010). The Impact of Terrorist Attacks on International Stock Markets. European Financial Management, 16(4), 585-598.

Brown, G. W., \& Cliff, M. T. (2005). Investor Sentiment and Asset Valuation. Journal of Business, $78(2), 405-440$.

Burch, T. R., Emery, D. R., \& Fuerst, M. E. (2003). What Can "Nine-Eleven" Tell Us about Closed-end Fund Discounts and Investor Sentiment? The Financial Review, 38(4), 515529.

Burch, T. R., Emery, D. R., \& Fuerst, M. E. (2016). Who Moves Markets in a Sudden Marketwide Crisis? Evidence from 9/11. Journal of Financial and Quantitative Analysis, 51(2), 463487.

Carhart, M. M. (1997). On Persistence in Mutual Fund Performance. Journal of Finance, 52(1), 57-82.

Carter, D. A., \& Simkins, B. J. (2004). The market's reaction to unexpected, catastrophic events: the case of airline stock returns and the September 11th attacks. The Quarterly Review of Economics and Finance, 44(4), 539-558. 
Chen, A. H., \& Siems, T. F. (2004). The effects of terrorism on global capital markets. European Journal of Political Economy, 20(2), 349-366.

Chermak, S. M., \& Gruenewald, J. (2007). The Media's Coverage of Domestic Terrorism. Justice Quarterly, 23(4), 428-461.

Chesney, M., Reshetar, G., \& Karaman, M. (2011). The impact of terrorism on financial markets: An empirical study. Journal of Banking and Finance, 35(2), 253-267.

Drakos, K. (2010). Terrorism activity, investor sentiment, and stock returns. Review of Financial Economics, 19(3), 128-135.

Eldor, R., \& Melnick, R. (2004). Financial markets and terrorism. European Journal of Political Economy, 20(2), 367-386.

Eldor, R., Hauser, S., Kroll, Y., \& Shoukair, S. (2012). Financial Markets and Terrorism: The Perspective of the Two Sides of the Conflict. Journal of Business Administration Research, $1(2), 18-29$.

Frijns, B., Verschoor, W. F., \& Zwinkels, R. C. (2017). Excess stock return comovements and the role of investor sentiment. Journal of International Financial Markets, Institutions \& Money, 49(1), 74-87.

Glaser, M., \& Weber, M. (2005). September 11 and Stock Return Expectations of Individual Investors. Review of Finance, 9(2), 243-279.

Hirshleifer, D., \& Shumway, T. (2003). Good Day Sunshine: Stock Returns and the Weather. Journal of Finance, 58(3), 1009-1032.

Huang, D., Jiang, F., Tu, J., \& Zhou, G. (2015). Investor Sentiment Aligned: A Powerful Predictor of Stock Returns. Review of Financial Studies, 28(3), 791-837.

Huang, D., Lehkonen, H., Pukthuanthong, K., \& Zhou, G. (2018). Sentiment Across Asset Markets. WP.

Johnston, R. B., \& Nedelescu, O. M. (2006). The impact of terrorism on financial markets. Journal of Financial Crime, 13(1), 7-25.

Jones, P. M., \& Olson, E. (2015). The International Effects of US Uncertainty. International Journal of Finance and Economics, 20(3), 242-252.

Kaplanski, G., \& Levy, H. (2010). Sentiment and stock prices: The case of aviation disasters. Journal of Financial Economics, 95(2), 174-201. 
Karolyi, G. A., \& Martell, R. (2006). Terrorism and the Stock Market. WP.

Kolari, J. W., \& Pynnonen, S. (2010). Event Study Testing with Cross-sectional. Review of Financial Studies, 23(11), 3996-4025.

Kothari, S. P., \& Warner, J. B. (2007). Econometric of Event Studies. Handbooks in Finance, 1, 3-36.

Markoulis, S., \& Katsikides, S. (2018). The Effect of Terrorism on Stock Markets: Evidence from the 21st Century. Terrorism and Political Violence, forthcoming.

Michaelides, A., Milidonis, A., \& Nishiotis, G. (2018). Private information in currency markets. Journal of Financial Economics, forthcoming.

Michaelides, A., Milidonis, A., Nishiotis, G., \& Papakyriakou, P. (2015). The adverse effects of systematic leakage ahead of official sovereign debt rating announcements. Journal of Financial Economics, 116(3), 526-547.

Nikkinen, J., \& Vahamaa, S. (2010). Terrorism and Stock Market Sentiment. The Financial Review, 45(2), 263-275.

Nikkinen, J., Omran, M. M., Sahlstrom, P., \& Aijo, J. (2008). Stock returns and volatility following the September 11 attacks: Evidence from 53 equity markets. International Review of Financial Analysis, 17(1), 27-46.

Papakyriakou, P., Sakkas, A., \& Taoushianis, Z. (2019). Financial Firm Bankruptcies, International Stock Markets and Investor Sentiment. International Journal of Finance \& Economics, 24(1), 461-473.

Pukthuanthong, K., \& Roll, R. (2009). Global market integration: An alternative measure and its application. Journal of Financial Economics, 94(2), 214-232.

Samarakoon, L. P. (2011). Stock market interdependence, contagion, and the U.S. financial crisis: The case of emerging and frontier markets. Journal of International Financial Markets, Institutions \& Money, 21(5), 724-742.

Saunders, E. M. (1993). Stock Prices and Wall Street Weather. The American Economic Review, 83(5), 1337-1345.

Schlenger, W. E., Caddell, J. M., Ebert, L., Jordan, B., Rourke, K. M., Wilson, D., . . Kulka, R. A. (2002). Psychological reactions to terrorist attacks: findings from the National Study of Americans' Reactions to September 11. JAMA, 288(5), 581-588. 
Schmeling, M. (2009). Investor sentiment and stock returns: Some international evidence. Journal of Empirical Finance, 16(3), 394-408.

Slone, M. (2000). Responses to Media Coverage of Terrorism. The Journal of Conflict Resolution, 44(4), 508-522.

Wang, A. Y., \& Young, M. (2017). Terrorist Attacks and Investor Risk Preference: Evidence from Mutual Fund Flows. WP.

Yu, J., \& Yuan, Y. (2011). Investor sentiment and the mean-variance relation. Journal of Financial Economics, 100(2), 367-381. 
Tables and Figures

Table 1: List of terrorist attacks (1998-2017)

\begin{tabular}{|c|c|c|c|c|c|}
\hline Ref & Date of Event & Country & City & Fatalities & Injuries \\
\hline 1 & $15 / 08 / 1998$ & United Kingdom & Omagh & 29 & 220 \\
\hline 2 & 17/02/1999 & Germany & Wilmersdorf & 3 & 43 \\
\hline 3 & 20/04/1999 & United States & Littleton & 15 & 24 \\
\hline 4 & $11 / 09 / 2001$ & United States & New York City & 2996 & 7366 \\
\hline 5 & $07 / 07 / 2005$ & United Kingdom & London & 56 & 784 \\
\hline 6 & $27 / 07 / 2008$ & United States & Knoxville & 2 & 7 \\
\hline 7 & $05 / 11 / 2009$ & United States & Killeen & 13 & 32 \\
\hline 8 & $18 / 02 / 2010$ & United States & Austin & 2 & 15 \\
\hline 9 & 05/08/2012 & United States & Oak Creek & 7 & 4 \\
\hline 10 & $15 / 04 / 2013$ & United States & Boston & 3 & 264 \\
\hline 11 & $19 / 04 / 2013$ & United States & Watertown & 2 & 16 \\
\hline 12 & $13 / 04 / 2014$ & United States & Overland Park & 3 & 0 \\
\hline 13 & $23 / 05 / 2014$ & United States & Isla Vista & 7 & 13 \\
\hline 14 & $22 / 10 / 2014$ & Canada & Saint-Jean-sur-Richelieu & 2 & 3 \\
\hline 15 & $13 / 11 / 2015$ & France & Paris & 93 & 217 \\
\hline 16 & $12 / 06 / 2016$ & United States & Orlando & 50 & 53 \\
\hline 17 & $14 / 07 / 2016$ & France & Nice & 87 & 433 \\
\hline 18 & $17 / 07 / 2016$ & United States & Baton Rouge & 4 & 3 \\
\hline 19 & $18 / 07 / 2016$ & Germany & Wurzburg & 1 & 5 \\
\hline 20 & $22 / 07 / 2016$ & Germany & Munich & 10 & 27 \\
\hline 21 & $26 / 07 / 2016$ & Japan & Sagamihara & 19 & 26 \\
\hline 22 & $19 / 12 / 2016$ & Germany & Berlin & 12 & 48 \\
\hline 23 & $22 / 05 / 2017$ & United Kingdom & Manchester & 23 & 119 \\
\hline 24 & 03/06/2017 & United Kingdom & London & 11 & 48 \\
\hline 25 & $19 / 06 / 2017$ & United Kingdom & London & 1 & 12 \\
\hline 26 & $12 / 08 / 2017$ & United States & Charlottesville & 1 & 19 \\
\hline 27 & $24 / 09 / 2017$ & United States & Antioch & 1 & 8 \\
\hline 28 & $01 / 10 / 2017$ & United States & Las Vegas & 59 & 851 \\
\hline
\end{tabular}


Table 2: List of countries - Stock market indices

This table lists the 66 countries with equity data in our sample. Thomson Reuters Markepsych Indices (TRMI) are available for all listed countries, since the 1st of January 1998, with the exception of Luxembourg, Slovakia and Slovenia.

\begin{tabular}{|c|c|c|c|c|c|}
\hline Ref & Country & Has TRMI & Ref & Country & Has TRMI \\
\hline 1 & Argentina & Yes & 34 & Malaysia & Yes \\
\hline 2 & Australia & Yes & 35 & Malta & Yes \\
\hline 3 & Austria & Yes & 36 & Mexico & Yes \\
\hline 4 & Bahrain & Yes & 37 & Morocco & Yes \\
\hline 5 & Belgium & Yes & 38 & Netherlands & Yes \\
\hline 6 & Brazil & Yes & 39 & New Zealand & Yes \\
\hline 7 & Bulgaria & Yes & 40 & Nigeria & Yes \\
\hline 8 & Canada & Yes & 41 & Norway & Yes \\
\hline 9 & Chile & Yes & 42 & Oman & Yes \\
\hline 10 & China & Yes & 43 & Pakistan & Yes \\
\hline 11 & Colombia & Yes & 44 & Peru & Yes \\
\hline 12 & Croatia & Yes & 45 & Philippines & Yes \\
\hline 13 & Cyprus & Yes & 46 & Poland & Yes \\
\hline 14 & Czech Republic & Yes & 47 & Portugal & Yes \\
\hline 15 & Denmark & Yes & 48 & Qatar & Yes \\
\hline 16 & Egypt & Yes & 49 & Romania & Yes \\
\hline 17 & Estonia & Yes & 50 & Russia & Yes \\
\hline 18 & Finland & Yes & 51 & Singapore & Yes \\
\hline 19 & France & Yes & 52 & Slovakia & No \\
\hline 20 & Germany & Yes & 53 & Slovenia & No \\
\hline 21 & Greece & Yes & 54 & South Africa & Yes \\
\hline 22 & Hong Kong & Yes & 55 & South Korea & Yes \\
\hline 23 & Hungary & Yes & 56 & Spain & Yes \\
\hline 24 & India & Yes & 57 & Sri Lanka & Yes \\
\hline 25 & Indonesia & Yes & 58 & Sweden & Yes \\
\hline 26 & Ireland & Yes & 59 & Switzerland & Yes \\
\hline 27 & Israel & Yes & 60 & Taiwan & Yes \\
\hline 28 & Italy & Yes & 61 & Thailand & Yes \\
\hline 29 & Japan & Yes & 62 & Turkey & Yes \\
\hline 30 & Jordan & Yes & 63 & UAE & Yes \\
\hline 31 & Kuwait & Yes & 64 & United Kingdom & Yes \\
\hline 32 & Lithuania & Yes & 65 & United States & Yes \\
\hline 33 & Luxembourg & $\mathrm{No}$ & 66 & Venezuela & Yes \\
\hline
\end{tabular}




\section{Table 3: Main analysis}

This table presents the Average Cumulative Abnormal Returns (ACAR) around the terrorist attacks listed in Table 1. ACAR is given in Equation (4). In the Overall case, we use all 28 terrorist attacks and equity data from all 66 countries in Table 2. In the cases of Negative and Positive Surprise, we use all the 28 terrorist attacks and equity data from the 63 countries with TRMI data (all countries in Table 2, excluding Luxembourg, Slovakia and Slovenia). Negative Surprise equals unity if the Cumulative Abnormal Sentiment (CAS) on day one post-event is negative; set to zero otherwise. Positive Surprise equals unity when the CAS on day one post-event is non-negative; set to zero otherwise. The CAS on day one post-event is the sum of the Abnormal Sentiment (AS) on days 0 and 1. AS is estimated by subtracting the average raw sentiment of trading days -10 to -2 from the raw sentiment relative to the event. T-stats and P-values are based on Kolari and Pynnonen (2010).

\begin{tabular}{cccc}
\hline & Overall & Negative Surprise & Positive Surprise \\
\hline Event window & ACAR & ACAR & ACAR \\
\hline$[-\mathbf{1 0}, \mathbf{- 1}]$ & $-0.011 \%$ & $-0.038 \%$ & $0.016 \%$ \\
{$[-\mathbf{5}, \mathbf{- 1}]$} & $0.043 \%$ & $-0.060 \%$ & $0.146 \%$ \\
{$[-\mathbf{3}, \mathbf{- 1}]$} & $0.086 \%$ & $-0.051 \%$ & $0.222 \%$ \\
{$[-\mathbf{2}, \mathbf{- 1}]$} & $0.033 \%$ & $-0.074 \%$ & $0.140 \%$ \\
{$[\mathbf{0},+\mathbf{1}]$} & $-0.414 \% * * *$ & $-0.508 \% * * *$ & $-0.320 \% * * *$ \\
{$[\mathbf{0},+\mathbf{2}]$} & $-0.442 \% * * *$ & $-0.553 \% * * *$ & $-0.329 \% * * *$ \\
{$[\mathbf{0},+\mathbf{3}]$} & $-0.491 \% * * *$ & $-0.613 \% * * *$ & $-0.369 \% * * *$ \\
{$[\mathbf{0},+\mathbf{5}]$} & $-0.536 \% * * *$ & $-0.592 \% * * *$ & $-0.480 \% * *$ \\
{$[\mathbf{0},+\mathbf{1 0}]$} & $-0.538 \% * * *$ & $-0.642 \% * * *$ & $-0.434 \% * *$ \\
{$[+\mathbf{1},+\mathbf{2}]$} & $-0.254 \% * * *$ & $-0.287 \% * * *$ & $-0.220 \% * *$ \\
{$[+\mathbf{1},+\mathbf{3}]$} & $-0.304 \% * * *$ & $-0.347 \% * * *$ & $-0.260 \% * *$ \\
{$[+\mathbf{1},+\mathbf{5}]$} & $-0.348 \% * *$ & $-0.326 \% * *$ & $-0.370 \% *$ \\
{$[+\mathbf{1},+\mathbf{1 0}]$} & $-0.350 \% *$ & $-0.376 \% *$ & $-0.324 \% *$ \\
{$[+\mathbf{2},+\mathbf{3}]$} & $-0.011 \%$ & $-0.105 \%$ & $-0.049 \%$ \\
{$[+\mathbf{2},+\mathbf{4}]$} & $0.039 \%$ & $-0.145 \%$ & $-0.073 \%$ \\
{$[+\mathbf{2},+\mathbf{5}]$} & $0.047 \%$ & $-0.084 \%$ & $-0.160 \%$ \\
{$[+\mathbf{+ 2},+\mathbf{1 0}]$} & $0.071 \%$ & $-0.134 \%$ & $-0.114 \%$ \\
{$[+\mathbf{3},+\mathbf{5}]$} & $-0.022 \%$ & $-0.038 \%$ & $-0.150 \%$ \\
{$[+\mathbf{3},+\mathbf{1 0}]$} & $0.003 \%$ & $-0.089 \%$ & $-0.104 \%$ \\
{$[+\mathbf{5},+\mathbf{1 0}]$} & $0.033 \%$ & $0.011 \%$ & $-0.041 \%$ \\
\hline
\end{tabular}

Notes: ${ }^{*} p$-value $<0.1,{ }^{* *} p$-value $<0.05,{ }^{* * *} p$-value $<0.01$ 
Table 4: Additional analysis - Testing the sample of events

This table presents Average Cumulative Abnormal Returns (ACAR) around the terrorist attacks listed in Table 1, using equity data from countries in Table 2. ACAR is given in Equation (4). In the Overall case, we consider all 28 terrorist attacks and use equity data from all 66 countries. In the Overall ex G7 case, we consider all 28 terrorist attacks and use equity data from 59 countries (all except the USA, the UK, Canada, France, Germany, Japan and Italy). In the Overall ex 9/11 case we consider 27 terrorist attacks (all except the 9/11 attack) and use equity data from all 66 countries. Finally, in the Overall ex 9/11 \& G7 case we consider 27 terrorist attacks (all except the 9/11 attack) and use equity data from 59 countries (all except the USA, the UK, Canada, France, Germany, Japan and Italy). T-stats and P-values are based on Kolari and Pynnonen (2010).

\begin{tabular}{|c|c|c|c|c|}
\hline & Overall & Overall ex G7 & Overall ex 9/11 & Overall ex 9/11 \& G7 \\
\hline Event window & ACAR & ACAR & ACAR & ACAR \\
\hline$[-10,-1]$ & $-0.011 \%$ & $0.004 \%$ & $0.065 \%$ & $0.080 \%$ \\
\hline$[-5,-1]$ & $0.043 \%$ & $0.050 \%$ & $0.101 \%$ & $0.109 \%$ \\
\hline$[-3,-1]$ & $0.086 \%$ & $0.086 \%$ & $0.105 \%$ & $0.106 \%$ \\
\hline$[-2,-1]$ & $0.033 \%$ & $0.032 \%$ & $0.052 \%$ & $0.052 \%$ \\
\hline$[0,+1]$ & $-0.414 \% * * *$ & $-0.437 \% * * *$ & $-0.356 \% * * *$ & $-0.380 \% * * *$ \\
\hline$[0,+2]$ & $-0.442 \% * * *$ & $-0.470 \% * * *$ & $-0.380 \% * * *$ & $-0.407 \% * * *$ \\
\hline$[0,+3]$ & $-0.491 \% * * *$ & $-0.524 \% * * *$ & $-0.383 \% * * *$ & $-0.414 \% * * *$ \\
\hline$[0,+5]$ & $-0.536 \% * * *$ & $-0.586 \% * * *$ & $-0.425 \% * * *$ & $-0.466 \% * * *$ \\
\hline$[\mathbf{0},+\mathbf{1 0}]$ & $-0.538 \% * * *$ & $-0.596 \% * * *$ & $-0.378 \% * *$ & $-0.421 \% * *$ \\
\hline$[+1,+2]$ & $-0.254 \% * * *$ & $-0.279 \% * * *$ & $-0.221 \% * * *$ & $-0.239 \% * * *$ \\
\hline$[+1,+3]$ & $-0.304 \% * * *$ & $-0.333 \% * * *$ & $-0.224 \% * *$ & $-0.245 \% * *$ \\
\hline$[+1,+5]$ & $-0.348 \% * *$ & $-0.395 \% * *$ & $-0.266 \% *$ & $-0.298 \% *$ \\
\hline$[+1,+10]$ & $-0.350 \% *$ & $-0.405 \% * *$ & $-0.219 \%$ & $-0.252 \%$ \\
\hline$[+2,+3]$ & $-0.011 \%$ & $-0.087 \%$ & $-0.027 \%$ & $-0.034 \%$ \\
\hline$[+2,+4]$ & $0.039 \%$ & $-0.124 \%$ & $-0.050 \%$ & $-0.053 \%$ \\
\hline$[+2,+5]$ & $0.047 \%$ & $-0.149 \%$ & $-0.069 \%$ & $-0.087 \%$ \\
\hline$[+2,+10]$ & $0.071 \%$ & $-0.159 \%$ & $-0.022 \%$ & $-0.041 \%$ \\
\hline$[+3,+5]$ & $-0.022 \%$ & $-0.116 \%$ & $-0.045 \%$ & $-0.059 \%$ \\
\hline$[+3,+10]$ & $0.003 \%$ & $-0.126 \%$ & $0.003 \%$ & $-0.014 \%$ \\
\hline$[+5,+10]$ & $0.033 \%$ & $-0.035 \%$ & $0.028 \%$ & $0.011 \%$ \\
\hline
\end{tabular}

Notes: ${ }^{*} p$-value $<0.1,{ }^{* *} p$-value $<0.05,{ }^{* * *} p$-value $<0.01$ 
Table 5: Additional analysis - Removing adjacent terrorism events

This table presents the Average Cumulative Abnormal Returns (ACAR) around 11 (out of 28) terrorist attacks listed in Table 1 . These are the attacks with reference numbers 1, 2, 5, 6, 7, 9, $10,12,14,15$ and 22. ACAR is given in Equation (4). In the Overall case, we use the 11 terrorist attacks and equity data from all 66 countries in Table 2. In the cases of Negative and Positive Surprise, we use the 11 terrorist attacks and equity data from the 63 countries with TRMI data (all countries in Table 2, excluding Luxembourg, Slovakia and Slovenia). Negative Surprise equals unity if the Cumulative Abnormal Sentiment (CAS) on day one post-event is negative; set to zero otherwise. Positive Surprise equals unity when the CAS on day one post-event is nonnegative; set to zero otherwise. The CAS on day one post-event is the sum of the Abnormal Sentiment (AS) on days 0 and 1 . AS is estimated by subtracting the average raw sentiment of trading days -10 to -2 from the raw sentiment relative to the event. T-stats and P-values are based on Kolari and Pynnonen (2010).

\begin{tabular}{|c|c|c|c|}
\hline & Overall & Negative Surprise & Positive Surprise \\
\hline Event window & ACAR & ACAR & ACAR \\
\hline$[-10,-1]$ & $0.039 \%$ & $-0.048 \%$ & $0.121 \%$ \\
\hline$[-5,-1]$ & $-0.059 \%$ & $-0.129 \%$ & $0.008 \%$ \\
\hline$[-3,-1]$ & $0.123 \%$ & $0.002 \%$ & $0.238 \%$ \\
\hline$[-2,-1]$ & $0.072 \%$ & $0.001 \%$ & $0.139 \%$ \\
\hline$[0,+1]$ & $-0.481 \% * * *$ & $-0.550 \% * * *$ & $-0.417 \% * *$ \\
\hline$[0,+2]$ & $-0.436 \% * * *$ & $-0.516 \% * * *$ & $-0.360 \% * *$ \\
\hline$[0,+3]$ & $-0.499 \% * *$ & $-0.601 \% * *$ & $-0.402 \% *$ \\
\hline$[0,+5]$ & $-0.631 \% * *$ & $-0.653 \% * *$ & $-0.610 \% *$ \\
\hline$[\mathbf{0},+\mathbf{1 0}]$ & $-0.786 \% * *$ & $-0.788 \% *$ & $-0.784 \% *$ \\
\hline$[+1,+2]$ & $-0.297 \% * *$ & $-0.321 \% * *$ & $-0.274 \% *$ \\
\hline$[+1,+3]$ & $-0.360 \% *$ & $-0.407 \% *$ & $-0.316 \%$ \\
\hline$[+1,+5]$ & $-0.492 \% *$ & $-0.458 \%$ & $-0.524 \% *$ \\
\hline$[+1,+10]$ & $-0.647 \% *$ & $-0.593 \%$ & $-0.699 \% *$ \\
\hline$[+2,+3]$ & $-0.018 \%$ & $-0.052 \%$ & $0.015 \%$ \\
\hline$[+2,+4]$ & $-0.102 \%$ & $-0.106 \%$ & $-0.099 \%$ \\
\hline$[+2,+5]$ & $-0.149 \%$ & $-0.103 \%$ & $-0.193 \%$ \\
\hline$[+2,+10]$ & $-0.305 \%$ & $-0.238 \%$ & $-0.368 \%$ \\
\hline$[+3,+5]$ & $-0.195 \%$ & $-0.137 \%$ & $-0.250 \%$ \\
\hline$[+3,+10]$ & $-0.350 \%$ & $-0.272 \%$ & $-0.425 \%$ \\
\hline$[+5,+10]$ & $-0.202 \%$ & $-0.133 \%$ & $-0.268 \%$ \\
\hline
\end{tabular}

Notes: ${ }^{*} p$-value $<0.1,{ }^{* *} p$-value $<0.05,{ }^{* * *} p$-value $<0.01$ 
Table 6: Additional analysis - Replicating Brounen and Derwall (2010)

This table presents the Average Cumulative Abnormal Returns (ACAR) around the terrorist attacks in Brounen and Derwall (2010). ACAR is given in Equation (4). In the Overall case, we use 31 terrorist attacks, over the years 1991-2005, and equity data from all the 66 countries in Table 2. In the cases of Negative and Positive Surprise we use a subset of 22, post-1998, terrorist attacks and equity data from the 63 countries with TRMI data (all countries in Table 2, excluding Luxembourg, Slovakia and Slovenia). Negative Surprise equals unity if the Cumulative Abnormal Sentiment (CAS) on day one post-event is negative; set to zero otherwise. Positive Surprise equals unity when the CAS on day one post-event is non-negative; set to zero otherwise. The CAS on day one post-event is the sum of the Abnormal Sentiment (AS) on days 0 and 1 . AS is estimated by subtracting the average raw sentiment of trading days -10 to -2 from the raw sentiment relative to the event. T-stats and P-values are based on Kolari and Pynnonen (2010).

\begin{tabular}{|c|c|c|c|}
\hline & Overall & Negative Surprise & Positive Surprise \\
\hline Event window & ACAR & ACAR & ACAR \\
\hline$[-10,-1]$ & $0.104 \%$ & $-0.118 \%$ & $0.405 \%$ \\
\hline$[-5,-1]$ & $-0.024 \%$ & $-0.272 \%$ & $0.353 \%$ \\
\hline$[-3,-1]$ & $0.059 \%$ & $-0.173 \%$ & $0.472 \%$ \\
\hline$[-2,-1]$ & $0.027 \%$ & $-0.161 \%$ & $0.272 \%$ \\
\hline$[0,+1]$ & $-0.259 \% * *$ & $-0.524 \% * * *$ & $-0.035 \%$ \\
\hline$[0,+2]$ & $-0.278 \% * *$ & $-0.501 \% * *$ & $0.072 \%$ \\
\hline$[0,+3]$ & $-0.411 \% * *$ & $-0.675 \% * *$ & $-0.103 \%$ \\
\hline$[0,+5]$ & $-0.403 \% * *$ & $-0.652 \% * *$ & $-0.174 \%$ \\
\hline$[0,+10]$ & $-0.497 \% *$ & $-0.791 \% *$ & $-0.309 \%$ \\
\hline$[+1,+2]$ & $-0.170 \%$ & $-0.303 \%$ & $0.028 \%$ \\
\hline$[+1,+3]$ & $-0.304 \% * *$ & $-0.477 \% * *$ & $-0.147 \%$ \\
\hline$[+1,+5]$ & $-0.295 \% *$ & $-0.453 \%$ & $-0.217 \%$ \\
\hline$[+1,+10]$ & $-0.390 \%$ & $-0.592 \%$ & $-0.353 \%$ \\
\hline$[+2,+3]$ & $-0.152 \%$ & $-0.151 \%$ & $-0.068 \%$ \\
\hline$[+2,+4]$ & $-0.127 \%$ & $-0.171 \%$ & $-0.040 \%$ \\
\hline$[+2,+5]$ & $-0.144 \%$ & $-0.128 \%$ & $-0.139 \%$ \\
\hline$[+2,+10]$ & $-0.238 \%$ & $-0.267 \%$ & $-0.274 \%$ \\
\hline$[+3,+5]$ & $-0.125 \%$ & $-0.151 \%$ & $-0.246 \%$ \\
\hline$[+3,+10]$ & $-0.219 \%$ & $-0.290 \%$ & $-0.381 \%$ \\
\hline$[+5,+10]$ & $-0.111 \%$ & $-0.096 \%$ & $-0.234 \%$ \\
\hline
\end{tabular}


Table 7: Additional analysis - Replicating Chesney et al. (2011)

This table presents the Average Cumulative Abnormal Returns (ACAR) around the terrorist attacks in Chesney et al. (2011). ACAR is given in Equation (4). In the Overall case, we use 77 terrorist attacks, over the years 1994-2005, and equity data from all the 66 countries in Table 2. In the cases of Negative and Positive Surprise we use a subset of 62, post-1998, terrorist attacks and equity data from the 63 countries with TRMI data (all countries in Table 2, excluding Luxembourg, Slovakia and Slovenia). Negative Surprise equals unity if the Cumulative Abnormal Sentiment (CAS) on day one post-event is negative; set to zero otherwise. Positive Surprise equals unity when the CAS on day one post-event is non-negative; set to zero otherwise. The CAS on day one post-event is the sum of the Abnormal Sentiment (AS) on days 0 and 1 . AS is estimated by subtracting the average raw sentiment of trading days -10 to -2 from the raw sentiment relative to the event. T-stats and P-values are based on Kolari and Pynnonen (2010).

\begin{tabular}{|c|c|c|c|}
\hline & Overall & Negative Surprise & Positive Surprise \\
\hline Event window & ACAR & ACAR & ACAR \\
\hline$[-10,-1]$ & $0.138 \%$ & $0.080 \%$ & $0.036 \%$ \\
\hline$[-5,-1]$ & $0.245 \% * *$ & $0.042 \%$ & $0.356 \%$ \\
\hline$[-3,-1]$ & $0.211 \% * *$ & $0.084 \%$ & $0.297 \% *$ \\
\hline$[-2,-1]$ & $0.130 \% *$ & $0.038 \%$ & $0.212 \% *$ \\
\hline$[0,+1]$ & $-0.014 \%$ & $-0.197 \% * * *$ & $0.135 \%$ \\
\hline$[0,+2]$ & $0.017 \%$ & $-0.195 \% * *$ & $0.174 \%$ \\
\hline$[0,+3]$ & $-0.028 \%$ & $-0.261 \% * * *$ & $0.107 \%$ \\
\hline$[0,+5]$ & $-0.073 \%$ & $-0.290 \% * *$ & $0.068 \%$ \\
\hline$[\mathbf{0},+\mathbf{1 0}]$ & $0.078 \%$ & $-0.240 \%$ & $0.265 \%$ \\
\hline$[+1,+2]$ & $0.037 \%$ & $-0.035 \%$ & $0.086 \%$ \\
\hline$[+1,+3]$ & $-0.008 \%$ & $-0.101 \% *$ & $0.019 \%$ \\
\hline$[+1,+5]$ & $-0.053 \%$ & $-0.131 \%$ & $-0.020 \%$ \\
\hline$[+1,+10]$ & $0.098 \%$ & $-0.080 \%$ & $0.177 \%$ \\
\hline$[+2,+3]$ & $-0.014 \%$ & $-0.064 \%$ & $-0.027 \%$ \\
\hline$[+2,+4]$ & $-0.014 \%$ & $-0.060 \%$ & $-0.078 \%$ \\
\hline$[+2,+5]$ & $-0.059 \%$ & $-0.093 \%$ & $-0.067 \%$ \\
\hline$[+2,+10]$ & $0.092 \%$ & $-0.043 \%$ & $0.131 \%$ \\
\hline$[+3,+5]$ & $-0.090 \%$ & $-0.095 \%$ & $-0.106 \%$ \\
\hline$[+3,+10]$ & $0.061 \%$ & $-0.045 \%$ & $0.092 \%$ \\
\hline$[+5,+10]$ & $0.106 \%$ & $0.018 \%$ & $0.209 \%$ \\
\hline
\end{tabular}

Notes: ${ }^{*} p$-value $<0.1,{ }^{* *} p$-value $<0.05,{ }^{* * *} p$-value $<0.01$ 
Table 8: Additional analysis - Accounting for size, value and momentum

This table presents the Average Cumulative Abnormal Returns (ACAR) around the terrorist attacks listed in Table 1. ACAR is given in Equation (4). The abnormal return (AR) is based on the global version of Carhart's (1997) four-factor model, which includes, in addition to the threefactor Fama-French model, the global momentum return. Everything else remains the same. In the Overall case, we use all 28 terrorist attacks and equity data from all 66 countries in Table 2. In the cases of Negative and Positive Surprise, we use all the 28 terrorist attacks and equity data from the 63 countries with TRMI data (all countries in Table 2, excluding Luxembourg, Slovakia and Slovenia). Negative Surprise equals unity if the Cumulative Abnormal Sentiment (CAS) on day one post-event is negative; set to zero otherwise. Positive Surprise equals unity when the CAS on day one post-event is non-negative; set to zero otherwise. The CAS on day one postevent is the sum of the Abnormal Sentiment (AS) on days 0 and 1. AS is estimated by subtracting the average raw sentiment of trading days -10 to -2 from the raw sentiment relative to the event. T-stats and P-values are based on Kolari and Pynnonen (2010).

\begin{tabular}{|c|c|c|c|}
\hline & Overall & Negative Surprise & Positive Surprise \\
\hline Event window & ACAR & ACAR & ACAR \\
\hline$[-10,-1]$ & $-0.186 \%$ & $-0.105 \%$ & $-0.268 \% *$ \\
\hline$[-5,-1]$ & $-0.045 \%$ & $-0.112 \%$ & $0.023 \%$ \\
\hline$[-3,-1]$ & $0.013 \%$ & $-0.113 \%$ & $0.140 \%$ \\
\hline$[-2,-1]$ & $-0.055 \%$ & $-0.150 \%$ & $0.041 \%$ \\
\hline$[0,+1]$ & $-0.330 \% * * *$ & $-0.432 \% * * *$ & $-0.227 \% * *$ \\
\hline$[0,+2]$ & $-0.262 \% * *$ & $-0.391 \% * * *$ & $-0.132 \%$ \\
\hline$[0,+3]$ & $-0.341 \% * *$ & $-0.487 \% * * *$ & $-0.194 \%$ \\
\hline$[\mathbf{0},+5]$ & $-0.284 \%$ & $-0.371 \% * *$ & $-0.195 \%$ \\
\hline$[0,+10]$ & $-0.259 \%$ & $-0.315 \%$ & $-0.202 \%$ \\
\hline$[+1,+2]$ & $-0.142 \% *$ & $-0.184 \% * *$ & $-0.099 \%$ \\
\hline$[+1,+3]$ & $-0.220 \% *$ & $-0.279 \% * *$ & $-0.161 \%$ \\
\hline$[+1,+5]$ & $-0.163 \%$ & $-0.164 \%$ & $-0.163 \%$ \\
\hline$[+1,+10]$ & $-0.139 \%$ & $-0.108 \%$ & $-0.169 \%$ \\
\hline$[+2,+3]$ & $-0.011 \%$ & $-0.055 \%$ & $0.034 \%$ \\
\hline$[+2,+4]$ & $0.039 \%$ & $-0.010 \%$ & $0.088 \%$ \\
\hline$[+2,+5]$ & $0.047 \%$ & $0.061 \%$ & $0.032 \%$ \\
\hline$[+2,+10]$ & $0.071 \%$ & $0.117 \%$ & $0.025 \%$ \\
\hline$[+3,+5]$ & $-0.022 \%$ & $0.020 \%$ & $-0.063 \%$ \\
\hline$[+3,+10]$ & $0.003 \%$ & $0.076 \%$ & $-0.070 \%$ \\
\hline$[+5,+10]$ & $0.033 \%$ & $0.127 \%$ & $-0.062 \%$ \\
\hline
\end{tabular}


Table 9: Additional Analysis - Accounting for the Beta instability

This table presents Average Cumulative Abnormal Returns (ACAR) around the terrorist attacks listed in Table 1. ACAR is given in Equation (4). The abnormal return (AR) is estimated by setting to unity the coefficient beta in the Equation (2). Everything else remains the same. In the Overall case, we use all 28 terrorist attacks and equity data from all 66 countries in Table 2 . In the cases of Negative and Positive Surprise, we use all the 28 terrorist attacks and equity data from the 63 countries with TRMI data (all countries in Table 2, excluding Luxembourg, Slovakia and Slovenia). Negative Surprise equals unity if the Cumulative Abnormal Sentiment (CAS) on day one post-event is negative; set to zero otherwise. Positive Surprise equals unity when the CAS on day one post-event is non-negative; set to zero otherwise. The CAS on day one post- event is the sum of the Abnormal Sentiment (AS) on days 0 and 1. AS is estimated by subtracting the average raw sentiment of trading days -10 to -2 from the raw sentiment relative to the event. T-stats and Pvalues are based on Kolari and Pynnonen (2010).

\begin{tabular}{|c|c|c|c|}
\hline & Overall & Negative Surprise & Positive Surprise \\
\hline Event window & ACAR & ACAR & ACAR \\
\hline$[-10,-1]$ & $0.102 \%$ & $0.130 \%$ & $0.074 \%$ \\
\hline$[-5,-1]$ & $0.128 \%$ & $0.034 \%$ & $0.222 \%$ \\
\hline$[-3,-1]$ & $0.154 \%$ & $0.037 \%$ & $0.272 \%$ \\
\hline$[-2,-1]$ & $0.098 \%$ & $0.002 \%$ & $0.193 \%$ \\
\hline$[0,+1]$ & $-0.388 \% * * *$ & $-0.473 \% * * *$ & $-0.302 \% * * *$ \\
\hline$[0,+2]$ & $-0.504 \% * * *$ & $-0.619 \% * * *$ & $-0.389 \% * * *$ \\
\hline$[\mathbf{0},+3]$ & $-0.554 \% * * *$ & $-0.660 \% * * *$ & $-0.447 \% * * *$ \\
\hline$[0,+5]$ & $-0.587 \% * * *$ & $-0.608 \% * * *$ & $-0.565 \% * * *$ \\
\hline$[0,+10]$ & $-0.602 \% * * *$ & $-0.639 \% * * *$ & $-0.564 \% * * *$ \\
\hline$[+1,+2]$ & $-0.357 \% * * *$ & $-0.398 \% * * *$ & $-0.316 \% * * *$ \\
\hline$[+1,+3]$ & $-0.407 \% * * *$ & $-0.439 \% * * *$ & $-0.374 \% * * *$ \\
\hline$[+1,+5]$ & $-0.440 \% * * *$ & $-0.388 \% * *$ & $-0.492 \% * * *$ \\
\hline$[+1,+10]$ & $-0.455 \% * *$ & $-0.419 \% * *$ & $-0.491 \% * *$ \\
\hline$[+2,+3]$ & $-0.166 \% *$ & $-0.187 \%$ & $-0.145 \%$ \\
\hline$[+2,+4]$ & $-0.183 \%$ & $-0.191 \%$ & $-0.174 \%$ \\
\hline$[+2,+5]$ & $-0.199 \%$ & $-0.136 \%$ & $-0.263 \%$ \\
\hline$[+2,+10]$ & $-0.214 \%$ & $-0.166 \%$ & $-0.262 \%$ \\
\hline$[+3,+5]$ & $-0.083 \%$ & $0.010 \%$ & $-0.176 \%$ \\
\hline$[+3,+10]$ & $-0.098 \%$ & $-0.020 \%$ & $-0.176 \%$ \\
\hline$[+5,+10]$ & $-0.032 \%$ & $0.025 \%$ & $-0.088 \%$ \\
\hline
\end{tabular}


Table 10: Additional analysis - Switching regimes

This table presents the Average Cumulative Abnormal Returns (ACAR) around the terrorist attacks listed in Table 1. ACAR is given in Equation (4). In the Overall case, we use all 28 terrorist attacks and equity data from all 66 countries in Table 2. In the cases of Negative and Positive Surprise, we use all the 28 terrorist attacks and equity data from the 63 countries with TRMI data (all countries in Table 2, excluding Luxembourg, Slovakia and Slovenia). Negative Surprise equals unity if the Cumulative Abnormal Sentiment (CAS) on day one post-event is negative; set to zero otherwise. Positive Surprise equals unity when the CAS on day one postevent is non-negative; set to zero otherwise. The CAS on day one post-event is the sum of the Abnormal Sentiment (AS) on days 0 and 1. AS is estimated by subtracting the average raw sentiment of trading days -10 to -2 from the raw sentiment relative to the event. T-stats and Pvalues are based on the methodology in Aktas et al. (2007).

\begin{tabular}{|c|c|c|c|}
\hline & Overall & Negative Surprise & Positive Surprise \\
\hline Event window & ACAR & ACAR & ACAR \\
\hline$[-10,-1]$ & $-0.159 \%$ & $-0.057 \%$ & $-0.263 \% * *$ \\
\hline$[-5,-1]$ & $0.013 \%$ & $-0.094 \%$ & $0.121 \%$ \\
\hline$[-3,-1]$ & $0.076 \%$ & $-0.031 \%$ & $0.183 \%$ \\
\hline$[-2,-1]$ & $0.005 \%$ & $-0.068 \%$ & $0.078 \%$ \\
\hline$[0,+1]$ & $-0.378 \% * * *$ & $-0.398 \% * * *$ & $-0.359 \% * * *$ \\
\hline$[0,+2]$ & $-0.327 \% * *$ & $-0.353 \% * *$ & $-0.300 \% * * *$ \\
\hline$[\mathbf{0},+3]$ & $-0.378 \% *$ & $-0.391 \% *$ & $-0.365 \% *$ \\
\hline$[0,+5]$ & $-0.457 \% *$ & $-0.388 \% *$ & $-0.527 \% *$ \\
\hline$[0,+10]$ & $-0.628 \% *$ & $-0.567 \%$ & $-0.689 \% * *$ \\
\hline$[+1,+2]$ & $-0.151 \% * * *$ & $-0.137 \% * *$ & $-0.165 \% * *$ \\
\hline$[+1,+3]$ & $-0.203 \%$ & $-0.175 \%$ & $-0.230 \%$ \\
\hline$[+1,+5]$ & $-0.282 \% *$ & $-0.172 \%$ & $-0.392 \%$ \\
\hline$[+1,+10]$ & $-0.452 \% *$ & $-0.351 \%$ & $-0.553 \% * *$ \\
\hline$[+2,+3]$ & $0.000 \%$ & $0.007 \%$ & $-0.007 \%$ \\
\hline$[+2,+4]$ & $-0.055 \%$ & $-0.072 \%$ & $-0.038 \%$ \\
\hline$[+2,+5]$ & $-0.079 \%$ & $0.010 \%$ & $-0.168 \%$ \\
\hline$[+2,+10]$ & $-0.250 \%$ & $-0.169 \%$ & $-0.330 \%$ \\
\hline$[+3,+5]$ & $-0.131 \%$ & $-0.035 \%$ & $-0.227 \%$ \\
\hline$[+3,+10]$ & $-0.301 \%$ & $-0.214 \%$ & $-0.389 \%$ \\
\hline$[+5,+10]$ & $-0.194 \% *$ & $-0.097 \%$ & $-0.292 \%$ \\
\hline
\end{tabular}

Notes: ${ }^{*} p$-value $<0.1,{ }^{* *} p$-value $<0.05,{ }^{* * *} p$-value $<0.01$ 
Table 11: Additional analysis - An alternative measure for Surprise

This table presents the Average Cumulative Abnormal Returns (ACAR) around the terrorist attacks listed in Table 1. ACAR is given in Equation (4). In the Overall case, we use all 28 terrorist attacks and equity data from all 66 countries in Table 2. In the cases of Negative and Positive Surprise\#2, we use all the 28 terrorist attacks and equity data from the 63 countries with TRMI data (all countries in Table 2, excluding Luxembourg, Slovakia and Slovenia). Negative Surprise\#2 equals unity if the Cumulative Difference in Sentiment (CDS) on day one post-event is negative, set to zero otherwise. Positive Surprise\#2 equals unity when the CDS on day one post-event is non-negative; set to zero otherwise. The CDS on day one post-event is the sum of the Difference in Sentiment (DS) on days 0 and 1. DS is the difference of the raw Sentiment (S) of two consecutive days (i.e. $\mathrm{DS}_{t}=\mathrm{S}_{\mathrm{t}}-\mathrm{S}_{\mathrm{t}-1}$ ). T-stats and P-values are based on Kolari and Pynnonen (2010).

\begin{tabular}{|c|c|c|c|}
\hline & Overall & Negative Surprise\#2 & Positive Surprise\#2 \\
\hline Event window & ACAR & ACAR & ACAR \\
\hline$[-10,-1]$ & $-0.011 \%$ & $0.004 \%$ & $-0.027 \%$ \\
\hline$[-5,-1]$ & $0.043 \%$ & $0.201 \%$ & $-0.115 \%$ \\
\hline$[-3,-1]$ & $0.086 \%$ & $0.168 \%$ & $0.003 \%$ \\
\hline$[-2,-1]$ & $0.033 \%$ & $0.111 \%$ & $-0.044 \%$ \\
\hline$[0,+1]$ & $-0.414 \% * * *$ & $-0.534 \% * * *$ & $-0.294 \% * * *$ \\
\hline$[0,+2]$ & $-0.442 \% * * *$ & $-0.518 \% * * *$ & $-0.365 \% * * *$ \\
\hline$[0,+3]$ & $-0.491 \% * * *$ & $-0.568 \% * * *$ & $-0.415 \% * * *$ \\
\hline$[0,+5]$ & $-0.536 \% * * *$ & $-0.616 \% * * *$ & $-0.456 \% * * *$ \\
\hline$[\mathbf{0},+\mathbf{1 0}]$ & $-0.538 \% * * *$ & $-0.694 \% * * *$ & $-0.382 \% * *$ \\
\hline$[+1,+2]$ & $-0.254 \% * * *$ & $-0.255 \% * * *$ & $-0.253 \% * * *$ \\
\hline$[+1,+3]$ & $-0.304 \% * * *$ & $-0.305 \% * *$ & $-0.302 \% * * *$ \\
\hline$[+1,+5]$ & $-0.348 \% * *$ & $-0.352 \% * *$ & $-0.344 \% * *$ \\
\hline$[+1,+10]$ & $-0.350 \% *$ & $-0.431 \% *$ & $-0.270 \%$ \\
\hline$[+2,+3]$ & $-0.011 \%$ & $-0.034 \%$ & $-0.121 \%$ \\
\hline$[+2,+4]$ & $0.039 \%$ & $-0.132 \%$ & $-0.087 \%$ \\
\hline$[+2,+5]$ & $0.047 \%$ & $-0.081 \%$ & $-0.162 \%$ \\
\hline$[+2,+10]$ & $0.071 \%$ & $-0.160 \%$ & $-0.088 \%$ \\
\hline$[+3,+5]$ & $-0.022 \%$ & $-0.098 \%$ & $-0.091 \%$ \\
\hline$[+3,+10]$ & $0.003 \%$ & $-0.176 \%$ & $-0.017 \%$ \\
\hline$[+5,+10]$ & $0.033 \%$ & $-0.028 \%$ & $-0.002 \%$ \\
\hline
\end{tabular}

Notes: ${ }^{*} p$-value $<0.1,{ }^{* *} p$-value $<0.05,{ }^{* * *} p$-value $<0.01$ 
Table 12: Additional analysis - Accounting for human loss

This table presents the Average Cumulative Abnormal Returns (ACAR) around the terrorist attacks listed in Table 1. ACAR is given in Equation (4). In the Overall case, we use all 28 terrorist attacks and equity data from all 66 countries in Table 2. In the cases of Negative and Positive Residual Surprise we use all the 28 terrorist attacks and equity data from the 63 countries with TRMI data (all countries in Table 2, excluding Luxembourg, Slovakia and Slovenia). Negative Residual Surprise equals unity if the Residual Cumulative Abnormal Sentiment (CAS) is negative; set to zero otherwise. Positive Residual Surprise equals unity when the Residual CAS is nonnegative; set to zero otherwise. The Residual CAS is the CAS less the expected CAS. The expected (or fitted) CAS is estimated following the regression of CAS on the natural logarithm of the number of fatalities reported with the terrorist attacks. Finally the CAS is the sum of the Abnormal Sentiment (AS) on days 0 and 1, relative to the event. AS is estimated by subtracting the average raw sentiment of trading days -10 to -2 from the raw sentiment relative to the event. T-stats and Pvalues are based on Kolari and Pynnonen (2010).

\begin{tabular}{|c|c|c|c|}
\hline & Overall & $\begin{array}{c}\text { Negative Residual } \\
\text { Surprise } \\
\end{array}$ & $\begin{array}{c}\text { Positive Residual } \\
\text { Surprise } \\
\end{array}$ \\
\hline Event window & ACAR & ACAR & ACAR \\
\hline$[-10,-1]$ & $-0.011 \%$ & $-0.039 \%$ & $0.022 \%$ \\
\hline$[-5,-1]$ & $0.043 \%$ & $-0.066 \%$ & $0.173 \%$ \\
\hline$[-3,-1]$ & $0.086 \%$ & $-0.042 \%$ & $0.238 \%$ \\
\hline$[-2,-1]$ & $0.033 \%$ & $-0.042 \%$ & $0.122 \%$ \\
\hline$[0,+1]$ & $-0.414 \% * * *$ & $-0.512 \% * * *$ & $-0.296 \% * * *$ \\
\hline$[0,+2]$ & $-0.442 \% * * *$ & $-0.526 \% * * *$ & $-0.341 \% * * *$ \\
\hline$[0,+3]$ & $-0.491 \% * * *$ & $-0.567 \% * * *$ & $-0.400 \% * * *$ \\
\hline$[0,+5]$ & $-0.536 \% * * *$ & $-0.500 \% * * *$ & $-0.579 \% * * *$ \\
\hline$[0,+10]$ & $-0.538 \% * * *$ & $-0.553 \% * *$ & $-0.520 \% * *$ \\
\hline$[+1,+2]$ & $-0.254 \% * * *$ & $-0.274 \% * * *$ & $-0.229 \% * * *$ \\
\hline$[+1,+3]$ & $-0.304 \% * * *$ & $-0.316 \% * *$ & $-0.289 \% * * *$ \\
\hline$[+1,+5]$ & $-0.348 \% * *$ & $-0.248 \%$ & $-0.467 \% * *$ \\
\hline$[+1,+10]$ & $-0.350 \% *$ & $-0.302 \%$ & $-0.408 \% * *$ \\
\hline$[+2,+3]$ & $-0.011 \%$ & $-0.055 \%$ & $-0.104 \%$ \\
\hline$[+2,+4]$ & $0.039 \%$ & $-0.063 \%$ & $-0.165 \%$ \\
\hline$[+2,+5]$ & $0.047 \%$ & $0.013 \%$ & $-0.283 \%$ \\
\hline$[+2,+10]$ & $0.071 \%$ & $-0.041 \%$ & $-0.224 \%$ \\
\hline$[+3,+5]$ & $-0.022 \%$ & $0.026 \%$ & $-0.238 \%$ \\
\hline$[+3,+10]$ & $0.003 \%$ & $-0.027 \%$ & $-0.179 \%$ \\
\hline$[+5,+10]$ & $0.033 \%$ & $0.022 \%$ & $-0.059 \%$ \\
\hline
\end{tabular}

Notes: ${ }^{*} p$-value $<0.1,{ }^{* *} p$-value $<0.05,{ }^{* * * *} p$-value $<0.01$ 
Table 13: Additional analysis - OLS regression

This table presents results from OLS regression analysis with the post-event Abnormal Return (AR) as the dependent variable and the post-event Abnormal Sentiment (AS), or Difference in Sentiment (DS), as the independent variable. $A_{t}$ is given in Equation (2). $A S_{t}$ is estimated by subtracting from the raw sentiment of trading day $t$, relative to the event, the average raw sentiment of trading days -10 to -2. $\mathrm{DS}_{\mathrm{t}}$ is the difference of the raw Sentiment $(\mathrm{S})$ in two consecutive days (i.e. $\mathrm{DS}_{\mathrm{t}}$ $\left.=S_{t}-S_{t-1}\right)$. The subscript " $t$ " denotes the relative to the event trading day and ranges from zero (0) to ten (10) in this occasion. We control for event and country-specific characteristics with indicator variables and for the heteroscedasticity of the error terms with White-Huber (heteroscedasticity robust) standard errors.

\begin{tabular}{|c|c|c|c|}
\hline \multicolumn{4}{|c|}{ Panel A. Abnormal Return and Abnormal Sentiment } \\
\hline & $\mathrm{AR}_{\mathrm{t}}$ & $\mathrm{AR}_{\mathrm{t}}$ & $\mathrm{AR}_{\mathrm{t}}$ \\
\hline$\overline{\mathrm{AS}_{\mathrm{t}}}$ & $\begin{array}{l}0.0108^{* * *} \\
(0.00110)\end{array}$ & $\begin{array}{l}0.0108^{* * * *} \\
(0.00109)\end{array}$ & $\begin{array}{l}0.0114^{* * * *} \\
(0.00116)\end{array}$ \\
\hline Volatilityt & & $\begin{array}{l}-0.138 \\
(0.365)\end{array}$ & $\begin{array}{l}-0.140 \\
(0.367)\end{array}$ \\
\hline Liquidity $_{t}$ & & & $\begin{array}{l}0.0000750 \\
(0.000119)\end{array}$ \\
\hline Constant & $\begin{array}{r}-0.00255 \\
(0.00156) \\
\end{array}$ & $\begin{array}{l}-0.00246^{*} \\
(0.00148) \\
\end{array}$ & $\begin{array}{l}-0.00277^{*} \\
(0.00160) \\
\end{array}$ \\
\hline Observations & 19765 & 19765 & 18895 \\
\hline Adj. R-Square & 0.0115 & 0.0116 & 0.0125 \\
\hline Ind. Variables & Country \& Event & Country \& Event & Country \& Event \\
\hline \multicolumn{4}{|c|}{ Panel B. Abnormal Return and Difference in Sentiment } \\
\hline & $\overline{\mathrm{AR}_{\mathrm{t}}}$ & $\overline{\mathrm{AR}_{\mathrm{t}}}$ & $\mathrm{AR}_{\mathrm{t}}$ \\
\hline$\overline{\mathrm{DS}_{\mathrm{t}}}$ & $\begin{array}{l}0.00712^{* * * *} \\
(0.000875)\end{array}$ & $\begin{array}{l}0.00713^{* * * *} \\
(0.000875)\end{array}$ & $\begin{array}{l}0.00749^{* * * *} \\
(0.000919)\end{array}$ \\
\hline Volatility & & $\begin{array}{l}-0.141 \\
(0.364)\end{array}$ & $\begin{array}{l}-0.144 \\
(0.366)\end{array}$ \\
\hline Liquidity & & & $\begin{array}{l}0.0000691 \\
(0.000119)\end{array}$ \\
\hline Constant & $\begin{array}{c}-0.00249 \\
(0.00156)\end{array}$ & $\begin{array}{c}-0.00240 \\
(0.00148)\end{array}$ & $\begin{array}{l}-0.00264^{*} \\
(0.00160)\end{array}$ \\
\hline Observations & 19746 & 19746 & 18876 \\
\hline Adj. R-Square & 0.00951 & 0.00960 & 0.0103 \\
\hline Ind. Variables & Country \& Event & Country \& Event & Country \& Event \\
\hline
\end{tabular}




\section{Figure 1: Average CAR (ACAR) vs Relative Date}

This figure plots Average Cumulative Abnormal Returns (ACAR) around the terrorist attacks in Table 1 using equity data from countries in Table 2. ACAR is given in Equation (4). For the Overall case, we consider all the 28 attacks in Table 1 across 66 stock market indices from countries in Table 2. For the Surprise cases, we consider all the 28 attacks in Table 1 across the 63 countries with TRMI data (all countries in Table 2, excluding Luxembourg, Slovakia and Slovenia). A plot of 28 randomly selected dates (to match the number and time span of the terrorist attacks in Table 1) across all 66 countries (in Table 2) is included for comparison purposes.

$0.400 \%$

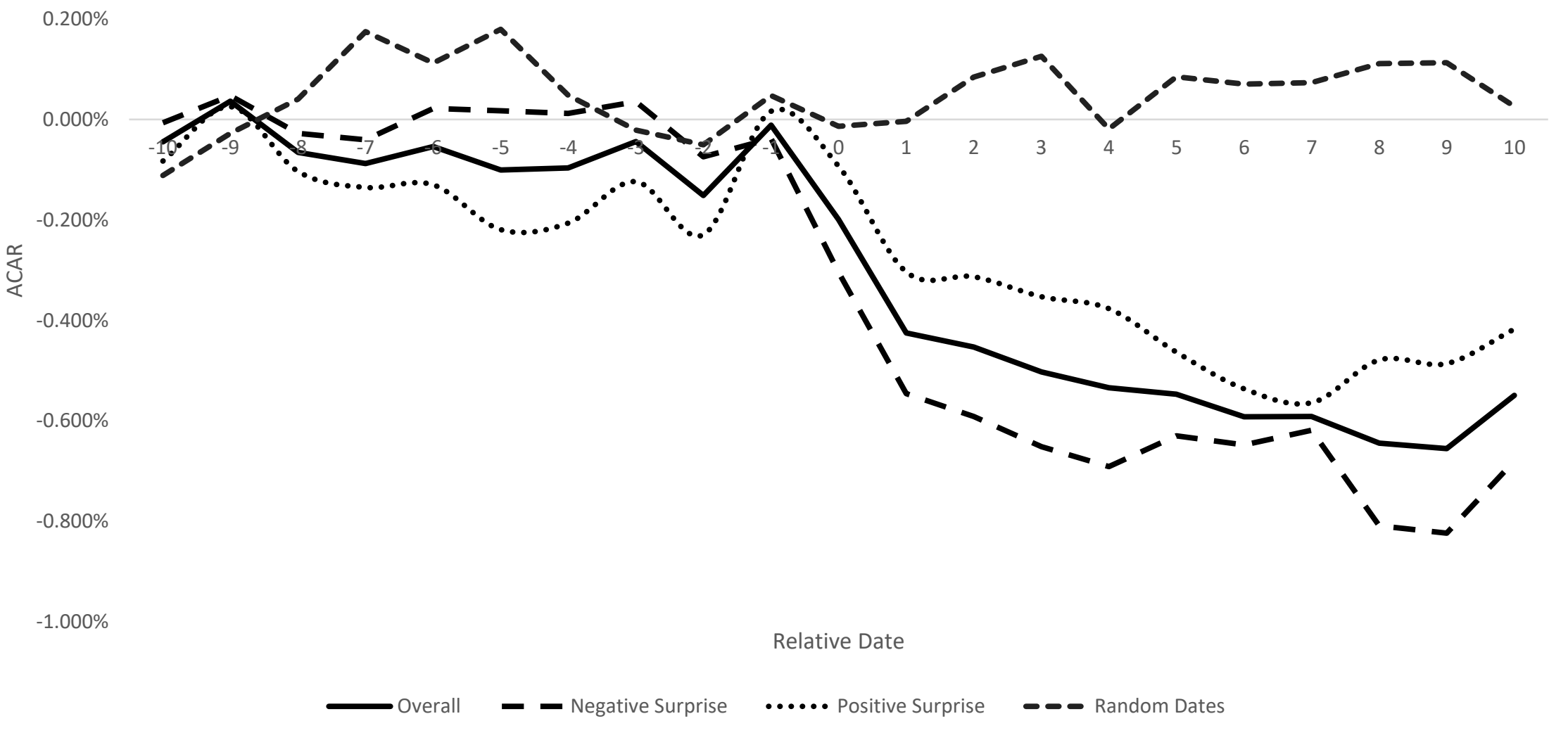


Figure 2: Average CAR (ACAR) vs relative date

This figure extends the post-event period in Figure 1. It plots Average Cumulative Abnormal Returns (ACAR) around the terrorist attacks in Table 1 using equity data from countries in Table 2. ACAR is given in Equation (4). For the Overall case, we consider all the 28 attacks in Table 1 across 66 stock market indices from countries in Table 2. For the Surprise cases, we consider all the 28 attacks in Table 1 across the 63 countries with TRMI data (all countries in Table 2, excluding Luxembourg, Slovakia and Slovenia). A plot of 28 randomly selected dates (to match the number and time span of the terrorist attacks in Table 1) across all 66 countries (in Table 2) is included for comparison purposes.

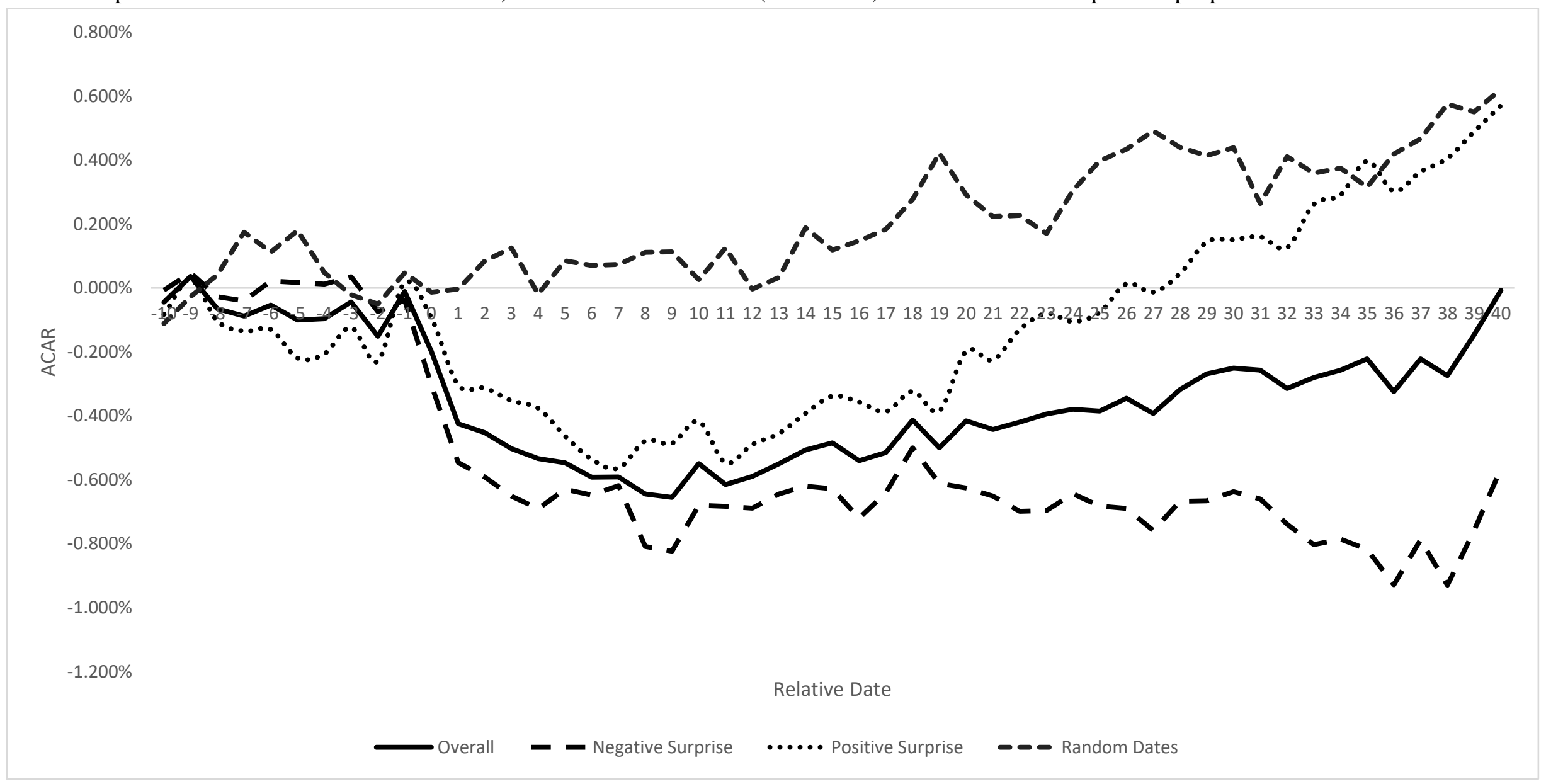

